Portland State University

PDXScholar

5-16-1986

\title{
Effect of Ethanol on Thermoregulation in the Goldfish Carassius auratus
}

Candace Sharon O'Connor

Portland State University

Follow this and additional works at: https://pdxscholar.library.pdx.edu/open_access_etds

Part of the Biology Commons, and the Physiology Commons Let us know how access to this document benefits you.

Recommended Citation

O'Connor, Candace Sharon, "Effect of Ethanol on Thermoregulation in the Goldfish Carassius auratus" (1986). Dissertations and Theses. Paper 3703.

https://doi.org/10.15760/etd.5587

This Thesis is brought to you for free and open access. It has been accepted for inclusion in Dissertations and Theses by an authorized administrator of PDXScholar. Please contact us if we can make this document more accessible: pdxscholar@pdx.edu. 
AN ABSTRACT OF THE THESIS of Candace Sharon O'Connor for the Master of Science in Biology presented May 16, 1986.

Title: Effect of Ethanol on Thermoregulation in the Goldfish, Carassius auratus.

\section{APPROVED BY MEMBERS OF THE THESIS COMMITTEE:}

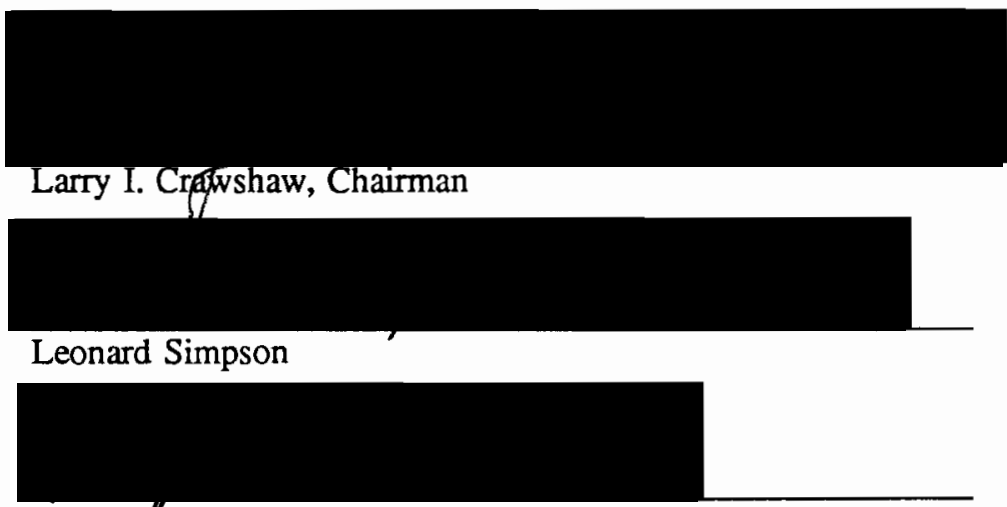

Philip $\boldsymbol{\alpha}$. Withers

In an attempt to elucidate the mechanism by which ethanol affects vertebrate thermoregulation, the effect of ethanol on temperature selection was studied in the goldfish, Carassius auratus. Ethanol was administered to 10 to $15 \mathrm{~g}$ fish by mixing it in the water of a temperature gradient. The dose response curve was very steep between $0.5 \%(\mathrm{v} / \mathrm{v})$ ethanol (no response) and $0.7 \%$ (significant lowering of selected temperature in treated fish). Fish were exposed to concentrations of ethanol as high as $1.7 \%$, at which concentration most experimental fish lost their ability to swim upright in the water. At concentrations higher than $0.7 \%$, the magnitude of the effect did not increase with increasing concentration of ethanol; treated animals continued to select temperatures about $2 \mathrm{C}$ below temperatures selected by controls. Experiments alternating exposure to $1.0 \%$ ethanol and water showed that the rate of onset and disappearance of the ethanol effect was rapid (within $10 \mathrm{~min}$ ). Other experiments exposing fish to $1.0 \%$ ethanol for up to $3 \mathrm{hr}$ showed that the effect remained stable for this period of time. The 
thermoregulatory responses of fish are behavioral, and therefore relatively easy to observe and quantify. Ethanol produces a prompt, stable and reproducible depression of selected temperature in the goldfish. Because the temperature at which fish regulate is controlled by a central nervous system set point and not altered by effects on peripheral effector systems, it appears that ethanol may cause hypothermia in goldfish by directly acting to lower the set point. 


\title{
EFFECT OF ETHANOL ON THERMOREGULATION IN THE GOLDFISH, CARASSIUS AURATUS
}

\author{
by \\ CANDACE SHARON O'CONNOR
}

A thesis submitted in partial fulfillment of the requirements for the degree of

\author{
MASTER OF SCIENCE \\ in \\ BIOLOGY
}

Portland State University

1986 
TO THE OFFICE OF GRADUATE STUDIES AND RESEARCH:

The members of the Committee approve the thesis of Candace Sharon O'Connor presented May 16, 1986.

Larry I. Crzhushaw, Chairman

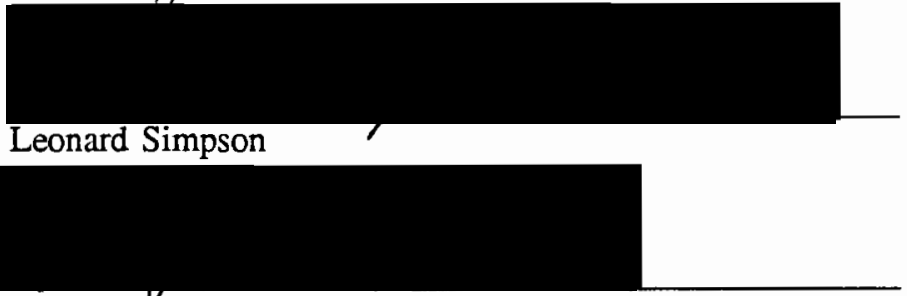

Philip C. KVithers

APPROVED:

Richard B.PPetersen, Head, Department of Biology

Bernard Ross, Dean of Graduate Studies and Research 


\section{ACKNOWLEDGEMENTS}

I would like to thank the members of my committee, Dr. Cord Sengstake, Dr. Leonard Simpson and Dr. Philip Withers, for their help in improving the accuracy and content of this thesis. I especially thank Dr. Withers for his advice about improved data presentation.

I am grateful for the support and good fellowship of all my fellow toilers in the lab. I especially thank Lonnie, Hercules and Rick for many good conversations about everything from fish pathology to Gary Larsen. I owe Lynda Lehnen and Suzanne Larsen a particular debt of gratitude for many hours of tireless and cheerful fish care, Xeroxing, sottering, and general improvement of the situation. I am also grateful to Dennis Grahn for his mastery of plumbing, carpentry and electrical skills and his generosity in using those talents to help others.

A special thanks goes to Dr. John C. Crabbe, who first had the idea of getting fish drunk. Thanks also to Cathy and Brenda in Dr. Crabbe's lab for running analyses that I could not perform in my own lab, and to Ann Kosobud for her kind advice.

I am especially grateful to all the kind people at Verdix West who made room for me on their system. I'll always remember Skipper with great affection!

My advisor, Dr. Larry Crawshaw, has given me unstinting support and understanding. His enthusiasm for physiology, appetite for hard work, and generosity with his time and considerable talents have made working for him a pleasure and an honor. I am very grateful for his help and encouragement.

I dedicate this thesis to Robert Bedichek. Without him, it would not exist. 
TABLE OF CONTENTS

PAGE

ACKNOWLEDGEMENTS

iii

LIST OF FIGURES

v

CHAPTER

I INTRODUCTION

II REVIEW OF THE LITERATURE

6

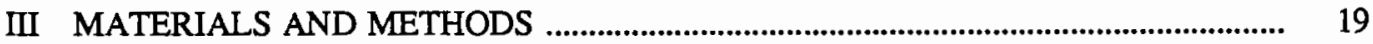

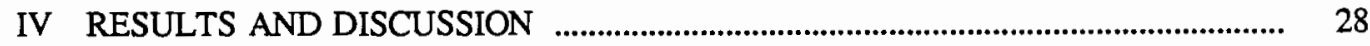

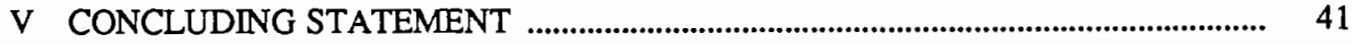

BIBLIOGRAPHY 


\section{LIST OF FIGURES}

FIGURE

PAGE

1. The Temperature Gradient

2. Information Flow in the Experimental System

3. Change in Ethanol Concentration with Time in the Temperature Gradient 23

4. Change in Ethanol Concentration in Fish Plasma over Time

5. Effect of Increasing Concentration of Ethanol on Selected Temperature of Goldfish (A)

$0.1 \%$ to $1.0 \%$ Ethanol (B) $0.8 \%$ to $1.7 \%$ Ethanol 29

6. Temperature Selected by Goldfish in Increasing Concentrations of Ethanol, Expressed as a Percent of Temperature Selected by Matching Control Fish 30

7. Effect of Exposure to $1.0 \%$ Ethanol for $3 \mathrm{hr}$ on Selected Temperature of Goldfish 33

8. Effect of Alternating Exposure to 1.0\% Ethanol and Water on the Temperature Selection of Goldfish 


\section{CHAPTER I}

\section{INTRODUCTION}

Ethanol produces a broad range of physiological effects in the human body. Acute effects that have been reported include:

- $\quad$ stimulation of secretion of gastric juices at low ethanol concentration (Daves et al, 1965; Elwin, 1969).

- $\quad$ irritation of gastric lining and inhibition of digestive enzymes at high concentration (Daves et al, 1965: Elwin, 1969).

- $\quad$ inhibition of enzyme secretion by the pancreas (Eckhardt et al, 1981).

- $\quad$ fleeting increase in heart rate and blood pressure at low concentration (Stein et al, 1963).

- reduction of contractile power of the heart and irregular electrocardiograms at high concentration (Ettinger et al, 1978).

- dilation of surface blood vessels and constriction of deep muscle vessels at low concentration (Wallgren and Barry, 1970).

- overproduction of insulin by the pancreas, and consequent hypoglycemia (Clark and Kricka, 1980).

- inhibition of pituitary release of antidiuretic hormone during rising blood alcohol concentration (Wallgren and Barry, 1970).

- inhibition of pituitary release of oxytocin (Wallgren and Barry, 1970).

- depressed erection and delayed or completely inhibited ejaculation (Wallgren and Barry, 1970). 
- antagonistic, additive, or supra-additive interactions with other drugs (Eckhardt et al, 1981).

- at blood alcohol content (BAC) of about $.05 \%$, relaxation, freedom from ordinary inhibitions and anxieties (NIAAA Second Special Report, 1976).

- at BAC of about $.10 \%$, impaired voluntary motor actions, increased reaction time to visual or auditory stimulus (NIAAA Second Special Report, 1976).

- at BAC of about $.20 \%$, significant depression of entire motor area of brain (NIAAA Second Special Report, 1976).

- $\quad$ at BAC of about .30\%, confused and stuporous behavior (NIAAA Second Special Report, 1976).

- at BAC of about $.40 \%$, coma (NIAAA Second Special Report, 1976).

- at BAC of $.50 \%$ or more, severe depression of medulla, often death by respiratory failure (Wallgren and Barry, 1970).

- hangover.

Reported effects of chronic ethanol ingestion include:

- development of tolerance (Eckhardt et al, 1981).

- cross-tolerance for numerous other drugs may occur; for example, alcoholics are much more difficult to anesthetize (Eckhardt et al, 1981).

- $\quad$ heightened response to some drugs (NIAAA Third Special Report, 1976).

- increased susceptibility to the toxic effects of certain compounds, such as carbon tetrachloride, which may be encountered in the workplace (Lieber, 1975).

- physical dependence on ethanol, with withdrawal symptoms which may be fatal when use is discontinued (Clark and Kricka, 1980).

- $\quad$ liver damage, including fatty liver, hepatitis, and cirrhosis (Brunt et al, 1974; Leevy, 1962).

- toxic effect on lining of the small intestine, and reduced absorption of nutrients (Clark and Kricka, 1980). 
- inflammation of the pancreas (Baum and Iber, 1973).

- primary malnutrition (decrease in actual consumption of nutrients) (Eckhardt et al, 1981).

- $\quad$ secondary malnutrition (food consumed is poorly digested and absorbed) (Eckhardt et al, 1981).

- Wernicke's encephalopathy, due to thiamin deficiency (Eckhardt et al, 1981).

- disorders of the peripheral nerves; burning, tender feet or hands, insensitivity to light touch (Eckhardt et al, 1981).

- deficits in memory, movement and coordination, perception and conceptual thinking (Eckhardt et al, 1981).

- $\quad$ enlarged and weakened heart (Eckhardt et al, 1981).

- $\quad$ high blood pressure (Beevers, 1977).

- $\quad$ stroke (Blackwelder et al, 1980).

- weakness and deterioration of the skeletal muscles (Song and Rubin, 1972).

- increased levels of estrogen and decreased levels of testosterone in men (Gordon and Southren, 1977).

- direct harmful effects on the testes and their normal function (NIAAA Fourth Special Reporth 1981).

- impotence (Gordon and Southren, 1977).

- disturbance in menstruation and failure of the ovaries to function (Gordon and Southren, 1977).

- higher incidence of infectious disease, especially tuberculosis (Edmondson, 1980).

- set of birth defects termed "fetal alcohol syndrome" in children born to mothers who drink heavily (Jones and Smith, 1973).

- poor nutrition in infants suckling drinking mothers due to decreased milk ejection and poor sucking ability in fetal alcohol syndrome afflicted babies (Cobo and Quintero, 1969; Martin et al, 
1979).

Ethanol also affects the very complex temperature regulation system of human beings. Intoxicated individuals are over-represented among the victims of accidental hypothermia (Kalant and Le, 1984), though often the actual cause of the hypothermia is not known. However, as is clear from the long preceding list of acute and chronic effects, ingestion of ethanol results in a wide variety of physiological and behavioral effects. A drunk person may fall asleep in an alley and die of "exposure" (hypothermia). Did the ethanol directly cause or accentuate physiological changes that resulted in hypothermia? Was the contribution of ethanol to alter behavior instead, depressing the central nervous system of the victim to the point where the will to get up and seek warm shelter was lacking?

Ethanol is a social lubricant and source of enjoyment for many people. Ethanol is also a problem in our society, a problem that carries with it a large price tag. In 1975 (from Eckhardt et al, 1981) there were an estimated ten million adult and three million youthful (aged fourteen to seventeen) problem drinkers and alcoholics in the United States. In that year, cirrhosis of the liver was the seventh most common cause of death in this country. More than a third of suicides involve alcohol. In 1979, alcohol in combination with other drugs was reported to be the most frequent cause of drug-related medical crisis in the United States. Mothers Against Drunk Driving (MADD) 1986 promotional pamphlets report that "drunk drivers killed 303 innocent people last year...in Oregon."

Because ethanol is such a widely abused drug, it has been studied in various ways for a long time. The effects of ethanol on temperature regulation have been studied at least since 1865 . It is clear that ethanol affects temperature regulation, but there is dispute about exactly what effect occurs. Many investigators claim that ethanol causes hypothermia, while others maintain that ethanol simply destroys the ability of an animal to regulate its temperature at all. The complexity of interrelated effects of ethanol in humans and other warm blooded animals makes unravelling of cause and effect a difficult proposition. Fish, however, are more straightforward in their thermoregulation. A thermostat in the fish brain is set to regulate at a certain temperature. If the fish is not fleeing from danger, very hungry, or 
otherwise desperate, it will try to obey the dictates of its thermostat by swimming into water of the appropriate temperature. Perhaps investigators over the past hundred years have been overlooking the animal best suited to the study of ethanol effects on thermoregulation. After all these years spent on rats, mice and rabbits, the effect of ethanol on central control of thermoregulation remains to be clarified. 


\section{CHAPTER II}

\section{REVIEW OF THE LITERATURE}

This review will begin with an examination of the work that established the existence and location of central nervous system controlling elements for temperature regulation. Specific thermoregulatory responses controlled by different structures in the nervous system will be examined. Temperature regulation in endotherms and ectotherms will be discussed and compared.

In 1961, James D. Hardy defined temperature regulation as "the maintenance of a temperature within a prescribed range under conditions of varying thermal loads." Hardy went on to state that the existence of temperature regulation clearly implies the existence of temperature sensitive cells as controlling elements. The search for those cells began over a hundred years ago.

In 1845 Bergman conceptualized heat sensitive brain structures that initiated thermoregulatory events (Euler, 1961). In 1884, Ott and Riche postulated "heat centers" in the brain which detected temperature deviations from normal and coordinated responses in such a way as to increase heat production in the cold, and increase heat loss in the heat (Hardy, 1961).

In 1895 , Aronsohn and Sachs observed a rise in the body temperature of rabbits after injury to the caudate nucleus (Bligh, 1966). This was the first clear indication of a discrete temperature-regulation center in the central nervous system.

Isenschmid and Krehl's work in 1912 demonstrated that temperature regulation fails when transection is made just anterior to the center of the optic thalamus. They postulated a posterior hypothalamic site at which afferent and efferent pathways for shivering are connected in the central nervous system. Soon after, in 1914, Isenschmid and Schnitzler found that normal temperature regulation 
required the integrity of the hypothalamus (Bligh, 1966).

Meyer, in 1913, postulated two coupled nerve centers, one thermogenic, one thermolytic, with reciprocal inhibition (Bligh, 1966). In 1939 Ranson and Magoun suggested two distinct regulatory centers and mechanisms; the anterior area of the hypothalamus, concerned with prevention of overheating, and the posterior area concerned with protection against the cold (Bligh, 1966).

Keller worked from 1932 to 1950 with animals in which he bilaterally extirpated the entire posterior hypothalamus. His recovered animals showed a large deficit in the ability to maintain body temperature; these lesions affected response to cold much more than response to heat (Hardy, 1961). Two groups working from 1936 to 1940, Frazier, Alpers and Lewy and also Clark, Magoun and Ranson, showed similar results. In addition, these investigators demonstrated that bilateral lesions in the anterior part of the lateral hypothalamus caused a marked loss of the ability to respond to heat with much less loss of the ability to respond to cold (Hardy, 1961).

As techniques progressed in sophistication from lesions and extirpation to localized thermal probing, certainty grew that the thermosensitive neurons are concentrated in the preoptic-anterior hypothalamic region of the brain (Hensel, 1973). Local thermal probing is an extremely powerful tool for study of central nervous control of thermoregulation. The whole brain can be heated or cooled by means of thermodes around the internal carotid arteries, or the preoptic-anterior hypothalamic tissue can be locally heated or cooled with a single large thermode placed in the midline or several small thermodes surrounding the preoptic-hypothalamic tissue (Hammel, 1968).

A large variety of thermoregulatory responses can be elicited in a number of different animals by localized heating and cooling of the preoptic-anterior hypothalamic region of the brain. Heating the hypothalamus can produce drowsiness, extension of the appendages, reduced metabolic rate, fur wetting, vasodilatation, panting, and increased sweating, heart rate, and blood pressure (Hammel, 1968; Hensel, 1973). Cooling the same area can cause increased rate of bar pressing for radiant heat in the rat, vasoconstriction, and shivering in the dog, rabbit and ox (Hammel, 1968), increased arterial and venous 
blood pressure and, in humans, increased serum potassium (Hardy, 1961).

Hormonal responses can be elicited by heating and cooling the preoptic-anterior hypothalamic region. Cooling causes a release of protein-bound iodine from the thyroid gland, increases the levels of norepinephrine and epinephrine in the urine and (over time) causes thicker fur growth in the goat, and produces water diuresis and a rise in plasma osmolality in the rhesus monkey (Hammel, 1968). Heating the hypothalamus causes the plasma norepinephrine and epinephrine levels in the ox to rise, and inhibits the appearance of urinary catecholamines and the release of protein-bound iodine in the goat (Hammel, 1968). Changes in catecholamine levels similar to those observed in goats have been found in pigs (Hensel, 1973).

Thermosensitive preoptic-anterior hypothalamic neurons function as powerful controllers for the elaborate physiological apparatus that senses and regulates the temperature of an organism. In 1939, Thauer proposed that the specific thermoregulatory control functions, though governed by the hypothalamus, are established in principle by structures widespread in the nervous system (Simon, 1974). Now it is known that other parts of the brain, including the medulla, the midbrain, the pons, and the posterior and lateral hypothalamus, assist in the regulation of body temperature (Crawshaw, 1980). An intact posterior hypothalamus, which is activated by the preoptic-anterior hypothalamic tissue, is required for shivering behavior (Hammel, 1968).

Spinal thermosensitivity is specifically related to the temperature regulation system (Simon, 1974). Many or all of the thermoregulatory responses elicited by heating or cooling the hypothalamus can also be elicited by heating or cooling the spinal cord of unanesthetized animals (Hensel, 1973). A change in the temperature of the spinal cord may influence thermoregulatory effector response without participation of the supraspinal control centers (Simon, 1974). Normal rhythmic shivering depends partly on an intact spinal cord (Hammel, 1968). Nonshivering thermogenesis can be induced in many mammals by cooling either the anterior hypothalamus or the spinal cord (Crawshaw et al, 1981).

Both heating and cooling can be detected by thermosensors located in the central nervous system, 
in the skin, and perhaps deep in the body (Hensel, 1973). Apparently, thermosensitive structures exist within the abdomen of the sheep and the squirrel monkey (Hensel, 1973). Heat sensors in the skin are the first to sense a change in the thermal environment (Crawshaw, 1980). Shivering can be inhibited and stimulated by a change in skin temperature, as well as by warming or cooling the thermoceptive structures in the hypothalamus (Euler, 1961). Goats, however, have not been made to shiver in a warm environment when the preoptic-anterior hypothalamic tissue is locally cooled, although vigorous panting can be activated in the goat by preoptic-anterior hypothalamic heating when the animal is in a cold room (Hammel, 1968).

The thermoregulatory system (taken from Hardy, 1961) in an organism is set, similar to a thermostat, to control body temperature at a certain level. Just where that regulated temperature is, is not yet clear. Many investigators have assumed that it is the hypothalamic temperature, but a more likely answer is that the regulated temperature is a result of an interplay of the effects of central and peripheral receptors (Hammel, 1968; Hardy, 1961; Hensel, 1973).

Because of varying thermal loads, body temperature often differs from set point temperature; the job of the temperature regulation system is to minimize the difference. Sensors detect changes in temperature. This signal reaches the controlling elements, which activate effector systems that move the body temperature closer to the set point. Feedback occurs along the line of control to increase the precision of the system.

Different basic types of control systems may be recognized in various physiological responses to temperature stress. An all-or-none response, like a relay opening and closing a switch to a heater circuit, is characteristic of many responses to heat and cold; shivering and panting may each occur in bursts, interspersed with periods of basal heat production or normal breathing. Large oscillations in temperature may occur in a system with large thermal lags when the only control is all-or-none.

Continuous proportional control provides for more stable temperature regulation. A relationship exists between the magnitude of the temperature error and the size of the effector action; greater error 
results in greater action. Under load, the controlled temperature must change from the set point to activate the system. This type of regulation has appealed to many physiologists as being most like physiologic temperature regulation, because as body temperature rises during exercise the cooling system seems to be driven in proportion to the difference between the temperature during exercise and the resting body temperature.

A system with integral control is characterized by a response to both the temperature displacement from the set point and the length of time the displacement has existed. This control scheme is probably not much used by physiological control systems. A temperature displacement that continues for some time at the same level, such as the displacement resulting from sustained exercise, does not drive the temperature controlling system to greater and greater efforts as the displacement continues.

Rate control is characterized by effector action proportional to the rate of change of the temperature. This control system is responsive only to rate; it will not control temperature at a fixed set point, but can recognize at once how great the thermal load will be. Peripheral receptors exhibit rate control; note, for example, the human reaction to touching something very hot. Rate control may be important physiologically in combination with proportional control.

An endotherm is an animal that is able to maintain its body temperature by internal heat production (Schmidt-Nielsen, 1983). Endotherms have evolved many behavioral and physiological strategies that enable them to keep their bodies within the preferred temperature range. The first response of an endotherm to a thermal stimulus is behavioral; when behavioral responses are not sufficient, autonomic responses are activated (Crawshaw et al, 1981). When they are too warm, endotherms increase blood flow, especially through skin, tongue and upper respiratory passages. Vascular convection of heat from the working muscles to the skin is a primary factor in heat exchange, while sweating and panting may also help certain animals to dissipate extra heat (Hardy, 1961). Some nonsweating animals such as cats, opossums (Hardy, 1961) and rats (Hainsworth, 1967) spread saliva on their fur to increase heat loss by evaporative cooling. 
Lessening vascular convection of heat to the skin by vasoconstriction is one way for an endotherm to conserve heat. In some animals with a thick fat layer, such as seals, vasoconstriction shunts blood to deeper tissues and away from the skin, enhancing the body insulation (Hardy, 1961). A cold animal that shivers to warm itself may elevate its oxygen consumption as much as $500 \%$ above resting value (Euler, 1961). The ability to increase nonshivering thermogenesis following exposure to cold is important in hibernators, unacclimatized and cold-acclimatized rats, newborn and adult guinea pigs, newborn rabbits and humans, and monkeys (Hammel, 1968). Certain of these animals' organs, especially brown fat stores, become more sensitive to the metabolic stimulation of increased levels of norepinephrine and thyroid hormones; the actual heat produced is probably a result of increased sodium pump activity (Guernsey and Stevens, 1977).

An ectotherm is an animal that depends on external heat sources, primarily direct or indirect solar radiation, to maintain body temperature (Schmidt-Nielsen, 1983). As with the endotherms, the first response of an ectotherm to a thermal stimulus is behavioral. But unlike endotherms, for most ectotherms behavioral responses also constitute the only means by which body temperature can be regulated. Although ectotherms cannot maintain their body temperature at the preferred level independent of their environment, being at the most favorable temperature is very important to them. Examples of biochemical and physiological processes in ectotherms that are optimal at or near the thermal preferendum include active metabolic rate, metabolic scope, oxygen debt load, maximum sustained speed, maximum volitional speed, growth rate, food conversion efficiency, resting and active blood pressure, active cardiac work, cardiac scope, elimination of anaerobically produced lactate, learning and memory, auditory sensitivity, appetite, digestion, immune response, renal function, hormone secretion and action, reproductive function and enzyme activity (Hutchison and Maness, 1979).

Some ectotherms have evolved non-behavioral methods for influencing their body temperatures. These physiological thermoregulatory strategies are typically utilized only in unusual or extreme situations, however, because there is some high cost associated with the benefit of the mechanism in question. Reptiles offer examples of physiological regulation of temperature which include both panting and 
jugular shunts to produce head-body temperature differences (Hutchison and Maness, 1979). During periods of high activity the metabolic rate of large monitor lizards exceeds resting levels found in endotherms of similar size (Hutchison and Maness, 1979). Brooding female pythons can produce heat by muscle tremors; they may consume as much as 9.3 times more oxygen when brooding than when not brooding, and produce a temperature excess of $4.7 \mathrm{C}$ above the ambient temperature (Hutchison and Maness, 1979). Crocodiles can increase cutaneous thermal conductance by increasing blood flow to the skin and subdermal musculature during warming, and decreasing blood flow during cooling (Smith, 1979); thus crocodiles, especially large ones, can increase their body temperature significantly while basking in cool, shallow water. Tunas possess countercurrent vascular pathways that serve to keep muscle temperature from $1 \mathrm{C}$ to $21 \mathrm{C}$ above the temperature of the surrounding water (Dizon and Brill, 1979), as do some lamnid sharks also (Hutchison and Maness, 1979). None of these methods, however, endow ectotherms with the degree of thermal independence of the environment that endotherms enjoy.

The behavioral strategies that ectotherms employ to keep their body temperatures within a liveable range are often abrogated in order to feed or to escape from danger. However, since so many physiological processes are optimal at the most favorable temperature, thermoregulation is a high behavioral priority for ectotherms. In fish, behavioral thermoregulation consists of swimming to a favorable water temperature; radiative and evaporative heat exchange do not occur in submerged fish (Beitinger and Fitzpatrick, 1979). Fish possess very sensitive temperature sensors in their skin which can detect changes as small as $0.03 \mathrm{C}$ (Bardach and Bjorklung, 1957), while a change of about $1.0 \mathrm{C}$ may motivate a fish to do work to readjust its environmental temperature (Crawshaw et al, 1981).

Once an unfavorable ambient temperature is detected, central controlling elements activate appropriate effector systems to move a fish to a more favorable thermal environment. Though the initial work done to establish the location of the central thermoregulatory controlling elements was done with mammals, more recent work has demonstrated that in fish, also, the anterior brainstem functions to regulate body temperature (Crawshaw et al, 1981). For example, Crawshaw and Hammel (1973) found that heating the rostral brain stem of the Brown bullhead Ameiurus nebulosus with implanted thermodes 
consistently caused the fish to regulate at a lower internal temperature. Cooling the brain in a similar fashion usually caused the fish to regulate at a higher temperature, though at times the fish became inactive in very cold water.

The next section of this review will examine the effects of ethanol and other drugs on body temperature. Volatile general anesthetics, opiates and opioids, and neuroleptics will be discussed. Mechanisms by which ethanol may affect cells will be considered. This review will conclude with an examination of the effects of ethanol on thermoregulation in whole animals, including endotherms and ectotherms.

In 1865 , A. Walther administered ethanol by gavage to rabbits. He observed that, in a cold (12.5 C) room, the rabbit's temperature fell to $20 \mathrm{C}$ in $2.5 \mathrm{hr}$; at this point the rabbit died (Freund, 1979). Today it is "common knowledge" that ingestion of ethanol leads to a feeling of warmth in people; it is also "common knowledge" that ethanol typically produces a lowering of body temperature in humans (Kalant and Le, 1984). After more than 100 years of investigations into the effects of ethanol on temperature regulation, however, the precise mechanism by which ethanol affects temperature regulation remains to be elucidated.

According to Euler (1961), ethanol is only one of many drugs that have a pharmacological effect on thermoregulatory mechanisms; sympathomimetics (ephedrine, amphetamine, cocaine) decrease rate of heat loss by causing vasoconstriction, while cholinomimetic agents (methacholine, pilocarpine, furtrethonium, acetylcholine) provoke a rise in evaporative heat loss. Ethanol is known to be among a group of drugs, including anesthetics, opioids, cannabinoids, monoamine oxidase inhibitors and phenothiazines, that affect the central nervous system and also impair the temperature-regulating centers (Freund, 1979).

Drugs that affect thermoregulation could do so by affecting the set point; the set point might be adjusted upwards or downwards, broadened, or abolished completely. In addition, thermoregulation could be affected if a drug acted to impair the functional capacity of thermoregulatory effectors. Such 
responses include metabolic thermogenesis, heat loss and heat conservation reflexes, and behavior that leads to temperature regulation (Freund, 1979). If a drug abolished the set point completely, one would expect an animal's temperature to drift with ambient temperature. If a drug acted to raise the set point, an endotherm would attempt, behaviorally and then physiologically, to raise its body temperature. A rat, for example, would move towards a source of heat. If it did not warm up very quickly the animal would also shiver, vasoconstrict, and erect its fur. If a drug acted to lower the set point, opposite behaviors and changes would occur as the rat cooled itself. A drug might leave the set point untouched, but act on an effector system. The animal would be placed in physiological conflict with itself if, for example, drug-induced vasodilation resulted in unwanted heat loss; a rat might attempt to defend its body temperature by piloerecting and approaching a heat source. The situation is somewhat different in the case of an ectotherm, such as a fish. If a drug abolished the set point of a fish, it would be expected to exhibit random temperature selection. If a drug acted to raise the set point of a fish, it would swim to warmer water; likewise, it would swim to cooler water if its set point were lowered. However if a drug acted to cause vasodilation, or increased respiratory frequency, and left the set point unchanged, the temperature of the fish would not change. It would continue to choose the environmental temperature dictated by its internal set point, its body temperature would remain at the temperature of its environment, and the affected system would not alter the temperature selection of the fish.

Ethanol, like other anesthetics, affects cell membrane properties (Rottenberg et al, 1981). The membranes of ethanol-dosed rats initially become much more fluid, but if ethanol dosing is continued, the membranes begin to exhibit greatly increased rigidity in the absence of ethanol. Ethanol tolerance and dependence probably result from these alterations in the membrane properties of the nervous system (Rottenberg et al, 1981). The net result is that membranes from ethanol-fed animals are about as fluid, in the presence of moderate amounts of ethanol, as are the membranes of control animals in the absence of ethanol (presumably a degree of fluidity that is optimal for membrane function). These membrane changes have been observed by Rottenberg et al in liver mitochondrial membranes, brain synaptosomal plasma membranes, and red blood cells. As membranes from ethanol-fed rats become more resistant to 
the disordering effects of ethanol, they also show reduced binding of ethanol. Rottenberg et al found, in addition, that resistance to binding of ethanol is associated with resistance to the binding of the general anesthetic halothane, as well as the sedative phenobarbital.

All of the volatile general anesthetics produce hypothermia (Kalant and Le, 1984). It must be remembered, however, that operating rooms are kept cool for the comfort of well insulated medical personnel equipped with surgical gowns, masks, and gloves. If general anesthetics act to destroy the set point, at low ambient temperature the net effect would be the same as if the set point were lowered. Like ethanol, general anesthetics decrease panting and shivering, hypothalamic blood flow, and preoptic-anterior hypothalamic neuron firing rates (Kalant and Le, 1984). Anesthetics probably impair temperature regulation by suppressing neuronal activity in the thermoregulatory cells (Freund, 1979). Pentobarbitol, a non-volatile hypnotic, may act on the same thermoregulatory mechanism in the brain as does ethanol; effects on the body temperature and metabolism of the rat are the same, tolerance to pentobarbitol is acquired along with tolerance to ethanol (cross-tolerance), and spontaneous loss of tolerance to ethanol (which occurs during very prolonged ethanol administration) is accompanied by a similar loss of tolerance to pentobarbitol (Kalant and Le, 1984).

Unlike ethanol and general depressants, opiates and opioids act through well-defined stereospecific receptors and intracellular second messengers, such as adenylate cyclase, and it might be expected that the effects of these agents on thermoregulation would be quite different from the effects of ethanol (Kalant and Le, 1984). This is true for many effects, but there are a few exceptions. In the rat, both chronic morphine and chronic ethanol depress the release of endogenous dopamine; also, chronic doses of ethanol that produce tolerance to ethanol induced hypothermia also produce tolerance to morphine induced hypothermia for large (though not small) doses of morphine, and the reverse cross tolerance also occurs (Kalant and Le, 1984). This may indicate that tolerance is a response to a drug induced functional disturbance, not to the drug itself; hypothermia itself then ought to give rise to tolerance to the hypothermic effect of diverse drugs, as well as to cold exposure (Kalant and Le, 1984). 
Another group of drugs, the neuroleptics, produce poikilothermia by directly blocking postsynaptic monoamine receptors (Kalant and Le, 1984); an example of this class of drugs is chlorpromazine, which has many effects similar to the effects of ethanol, including suppression of shivering and reduction of the metabolic response to cold. Long-term chlorpromazine administration results in the development of some tolerance to the effects of ethanol, and vice versa (Kalant and Le, 1984).

As has been discussed, the effects of ethanol on thermoregulation resemble the effects of other drugs whose mechanisms of action are understood. Unfortunately, similar mechanisms of action cannot automatically be inferred from observed similarity of effect. These different drugs, with different mechanisms of action, may produce overlapping effects on thermoregulation and overlapping crosstolerance with ethanol because the stimulus to tolerance is the common thermoregulatory end effect, rather than the particular molecular mechanism by which the drug takes effect (Kalant and Le, 1984). Perhaps different types of tolerance exist. Rottenberg et al's (1981) work with membrane fluidity may reveal one kind of ethanol tolerance, a generalized tolerance to the disordering effects of ethanol and the volatile central depressants on cell membranes that comes about through a change in the lipid constituents of the membrane. Specific tolerance to hypothermic effects, or other specific physiological effects, may be a separate sort of tolerance that indeed is somehow a result of exposure to the effect, no matter how induced, not to the cause. But the potency of any drug that exerts its effects via the membrane, as neuroleptics do by blocking post-synaptic monoamine receptors, and opiates and opioids do through stereospecific receptors and second messengers, might be altered if the physical characteristics of the cell membrane are altered. This may explain how exposure to ethanol might cause crosstolerance to any one of these drugs. It is more difficult to explain the opposite case, an opiate or neuroleptic causing cross-tolerance to ethanol, in just the same way.

An attempt by Mancillas et al (1986) to provide insight into the synaptic mechanisms underlying the effect of ethanol intoxication on behavior involved testing rat hippocampal cells in situ by iontophoresis of several neurotransmitters. Ethanol had no significant effect on excitatory responses to glutamate or inhibitory responses to $\gamma$-aminobutyric acid, but ethanol did significantly enhance excitatory 
responses to acetylcholine and inhibitory responses to somatostatin-14. Ethanol facilitates excitatory synaptic transmission at the vertebrate neuromuscular junction and (at low doses) at the frog sympathetic ganglia, where acetylcholine is the neurotransmitter; ethanol also depresses acetylcholinemediated collateral transmission in the Mauthner cell of the goldfish and (in high doses) at the frog sympathetic ganglia (Mancillas et al, 1986). As Mancillas et al point out, the postsynaptic actions of a transmitter can be altered by several factors, including interactions with other transmitters and the state of the postsynaptic membrane. Any of the factors that change postsynaptic responses to neurotransmitters could be the primary target of ethanol; "in spite of considerable research, the basic neuronal mechanisms underlying ethanol intoxication, tolerance, and dependence remain to be elucidated."

The effects of ethanol on thermoregulation of whole animals are "complex, incompletely understood, and subject to modification by a number of internal and external variables" (Kalant and Le, 1984). Ethanol has been shown to modify many major thermoregulatory elements, including nonshivering thermogenesis, shivering, respiratory depth and frequency, cutaneous blood flow, sweat secretion, firing rates of neurons, and behavior (Kalant and Le, 1984). Experimental studies on humans indicate that mild intoxication produces hypothermia when coupled with hard exercise and low ambient temperature (Haight and Keatinge, 1973; Kalant and Le, 1984). The normal body temperature of the rat (and other rodents) is about $37 \mathrm{C}$ (Freund, 1979). Small mammals dosed with ethanol suffer marked hypothermia at ambient temperatures below their thermoneutral zone (which includes "normal" room or lab temperature of about $25 \mathrm{C}$ ), but at high ambient temperature, ethanol produces hyperthermia in rats and mice (Kalant and Le, 1984; Myers, 1981). These results seem to suggest that the effect of ethanol on thermoregulation is to impair or negate the central thermoregulatory control system. Myers (1981) found, in a series of experiments done on rats, that the animals' colonic temperature would actually follow the ambient temperature, within limits. Since poikilothermic is defined (Funk \& Wagnalls, 1973) as "Having blood that varies in temperature in accordance with that of the surrounding medium", Myers felt he had ample justification to state (1981) "the physiological mechanisms for the dissipation of body heat as well as those for heat production are incapacitated by the drug. Clearly, alcohol is a 
poikilothermic agent..."

To examine only the effect of ethanol on central nervous system control of thermoregulation, somehow the effects on central controlling elements must be isolated from effects on the whole suite of peripheral effector systems. Evidence indicates that "central neural control mechanisms governing thermoregulation are similar and probably homologous among all vertebrate classes" (Reynolds and Casterlin, 1979). If this is so, fish are excellent subjects for studies of the effects of ethanol on central nervous system control of temperature regulation. In mammals, a change in set point can result in the initiation of behavioral and physiological responses that lead to an increase or decrease in body temperature. In contrast, as Neill (1979) says so well, "As a group, fishes have at their disposal only one effective means of regulating body temperature: behavioral thermoregulation of immediate environmental temperature. This form of behavioral thermoregulation necessarily involves locomotory movements." In addition, and perhaps most importantly, the disruption of peripheral thermoregulatory effector systems in the fish is not possible, since they do not exist. Vasodilation may occur, for example, but it will never cool the fish, whose body temperature will remain essentially that of the water in which it swims. If a fish is free to choose the thermal environment it prefers, as in a temperature gradient, its behavioral responses to perturbations of the central thermoregulatory controllers (including the administration of ethanol) can be accurately recorded, and quantified with relative ease. 


\section{CHAPTER III}

\section{MATERIALS AND METHODS}

\section{Animals}

Ozark Fisheries in Stoutland, Missouri supplied the ten to fifteen gram (ten to twelve $\mathrm{cm}$ ) goldfish (Carassius auratus) used in these studies. The fish were housed, fifty to a tank, in 135 liter opaque plastic outdoor tanks. They were exposed to the natural photoperiod. Fish water was kept at approximately $23 \mathrm{C}$, and continuously circulated through a composite filter consisting of a thin layer of cotton floss (particle filter) over a deep bed of small rocks (biological filter). One half of the water in each tank was changed once a week. Water $\mathrm{pH}$ averaged slightly above neutral. Water from the local reservoir was very soft, so salts $(\mathrm{NaCl}$ and trace $\mathrm{KI})$ were added to increase water hardness to equal the mean hardness of United States river water $(2.8 \mathrm{mg} / \mathrm{l})$. Fish were fed Tetra bulk tropical fish flakes every other day. They were never fed within thirty hours of an experiment.

Experimental fish that were reused were always allowed a minimum of two weeks in their home tanks between experiments, to ensure avoidance of any possible tolerance effects. This period of time was more than sufficient. Ryback et al (1969) demonstrated that after two hours in water, the blood ethanol levels of fish which had been exposed to $0.62 \%$ ethanol for six hours had decreased to about $0.1 \%$ ethanol. Greizerstein and Smith (1973) found that five hours after termination of an experiment in which the fish were kept in $0.8 \%$ ethanol solution, the brain ethanol content approached zero.

\section{Experimental apparatus}

Temperature selection of the fish was ascertained in a water-filled temperature gradient. The gradient was filled with fresh water before each day of use. The water was dechlorinated and salt was 
added, as for the fish tank water. At the end of each day of use the gradient was drained and thoroughly rinsed.

The gradient was composed of nine adjacent, separate lanes, each about $240 \mathrm{~cm} \mathrm{X} 24 \mathrm{~cm}$ with a depth of $16 \mathrm{~cm}$ (Figure 1).

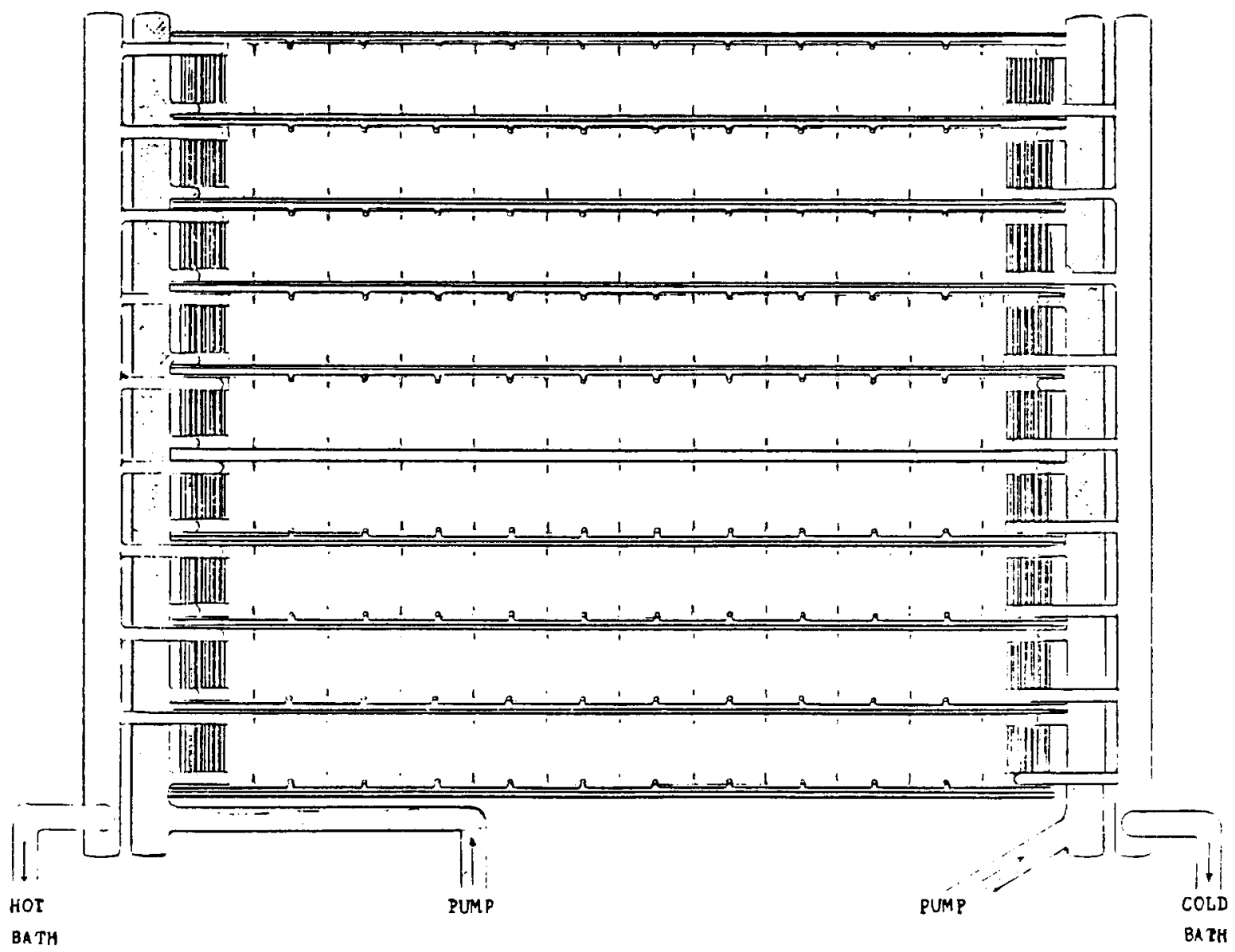

Figure 1. The temperature gradient.

Submerged in both ends of each lane were heat exchangers coupled by circulating pumps to a hot or cold source. Wire mesh barriers kept the fish away from the heat exchangers. Baffles divided each lane into ten chambers of equal length. Each chamber was vigorously aerated to prevent the development of thermal stratification. Continuous monitoring of the voltage produced by copper-constantin thermocou- 
ples (ice bath reference) on a Linear strip chart recorder showed that the temperature within the gradient was stable within $+/-0.5 \mathrm{C}$ for the duration of the experiment. The complete temperature profile for each lane of the gradient was established by measuring the temperature at the geometric center of each chamber at the end of every experiment.

All lanes were continuously and simultaneously monitored by a Panasonic WV-1854 high resolution television camera equipped with a wide angle lens (Figure 2). The camera signal was fed to a Panasonic NV-8050 time lapse video cassette recorder, coupled to a Panasonic WV-5410 video monitor for real-time viewing of fish behavior.

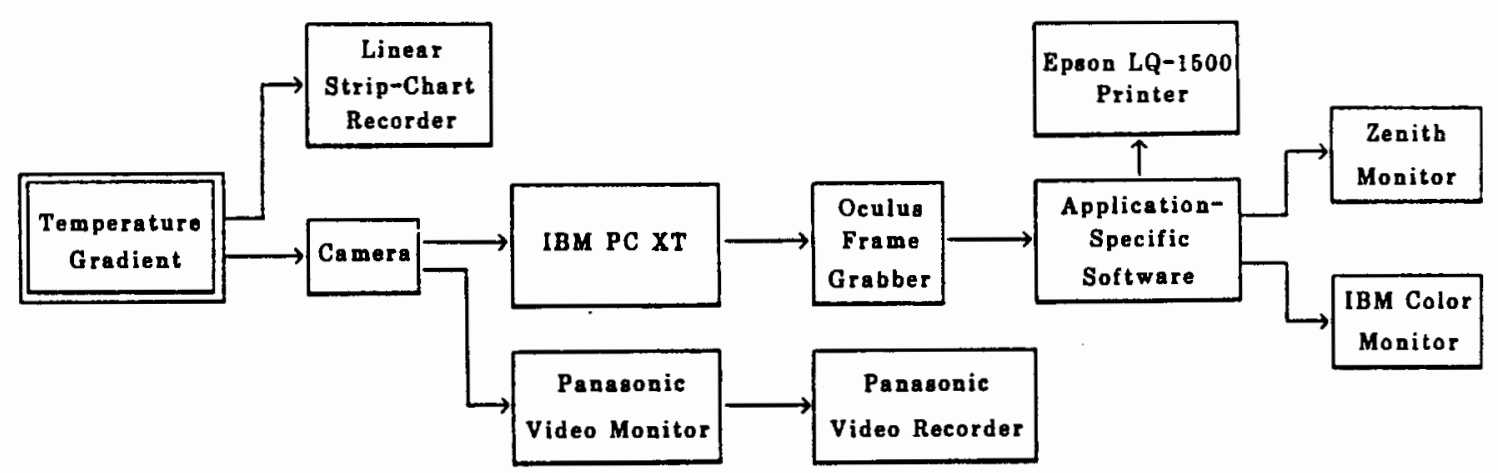

Figure 2. Information flow in the experimental system.

The signal from the camera was also fed into an IBM PC XT equipped with an Oculus frame grabber (Coreco Company). Application-specific software translated fish positions into a digital color display on an IBM color monitor, and an analog display on a neighboring Zenith monitor. A continuous printed trace of all fish positions, updated every five seconds, was produced by an Epson LQ-1500 dot matrix printer. A binary file containing the information describing all fish positions throughout the course of the experiment was stored on an IBM 20 megabyte hard disk. The files of fish position as a function of time were readily accessible through an editing program. The temperatures measured during calibration for all chambers of each lane in the gradient were used by the editing program to automatically translate fish positions into corresponding temperature values for data analysis. 


\section{Experimental Protocol}

Before and between days of experiments, fish were trained in the gradient to accustom them to the temperature gradient and to being alone in a novel environment. On the morning of behavioral experiments, nine trained fish were removed from the holding tanks in a bucket. The fish were caught in random order and released in the gradient, one to a lane. They were allowed to swim freely and reaccustom themselves to the gradient for a minimum of 45 minutes before ethanol was added.

The protocol for all behavioral experiments was similar. After the initial equilibration period, each fish was netted and placed in a covered mesh corral inserted into each lane at approximately the position of the fish's preferred temperature. Once all fish were secured, the desired concentration of ethanol was added to the lanes containing the experimental fish. An appropriate volume of 95 percent ethanol was dispensed using a VWR Dispenser 511. The total dose calculated for each lane was divided into eleven equal portions. Each chamber received one portion. The one remaining portion was divided evenly between the two ends of each lane where the heat exchangers were located. A plastic wisk was used to thoroughly mix water and ethanol in each chamber without disturbing the temperature separation between chambers. After all chambers in control and experimental lanes were carefully mixed, the corrals were lifted gently upwards out of the lanes, freeing the fish.

Figure 3 illustrates the change in ethanol concentration with time that occurs in the water of the temperature gradient. The change in ethanol concentration was monitored in three lanes of the gradient for six hours. Analysis of covariance (Zar, 1974) showed that the rate of change in concentration was not different for the lanes tested. Figure 3 shows representative data collected from lane 2. Immediately after wisking was complete, the first samples were taken from three locations, the longitudinal centers of the coldest, middle, and hottest chambers (approximately 7.6, 22.4, and $31.2 \mathrm{C}$, respectively). Samples were collected in $1.5 \mathrm{ml}$ snap tubes and immediately frozen. Ethanol concentrations were assayed by gas chromatography, with assays conducted by technicians in John C. Crabbe's laboratory at the Veteran's Administration Hospital in Portland, Oregon (Crabbe et al, 1982). The spread in initial 


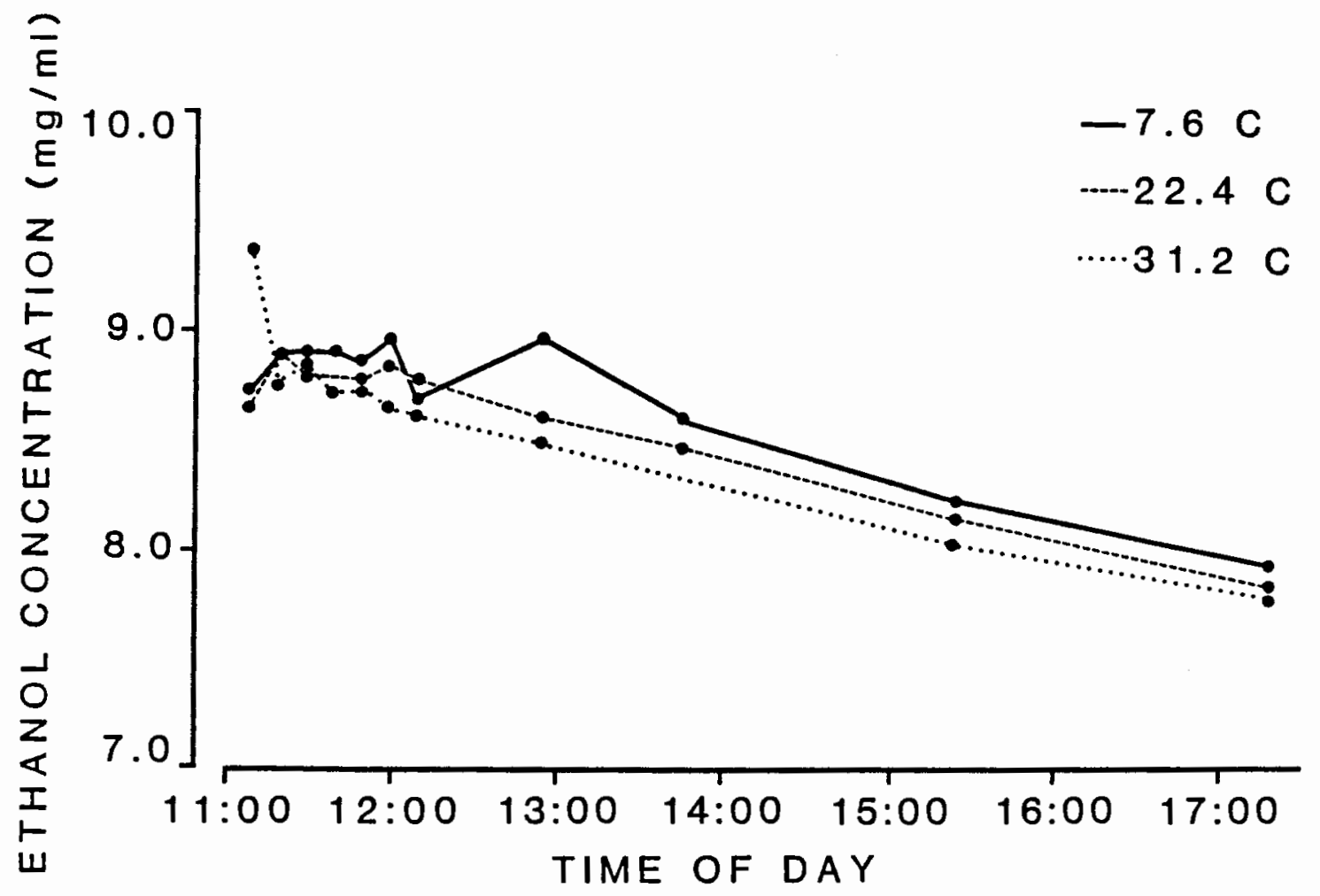

Figure 3. Change in ethanol concentration with time in the temperature gradient.

concentrations between the three locations indicates that wisking did not perfectly mix the ethanol and water. The second samples taken, ten minutes after the ethanol was first added, were similar in ethanol concentration and show that the ethanol had been distributed evenly throughout the lane. The usual experimental procedure of adding ethanol to each chamber, wisking each chamber, then releasing the fish in the order in which they were caught and caged consumed approximately seven minutes. By the time fish were released for data collection, therefore, they were confronted with water containing a nearly uniform concentration of ethanol.

Over the time of this experiment, more than six hours, the ethanol concentration decreased a maximum of about $0.1 \%$ in the hottest chamber, with a slightly smaller decrease observed in the cooler chambers sampled. The question of whether this decrease is significant to any of the experiments conducted can best be answered after an examination of Figure 4. 
Figure 4 illustrates the change in ethanol concentration of fish plasma over time.

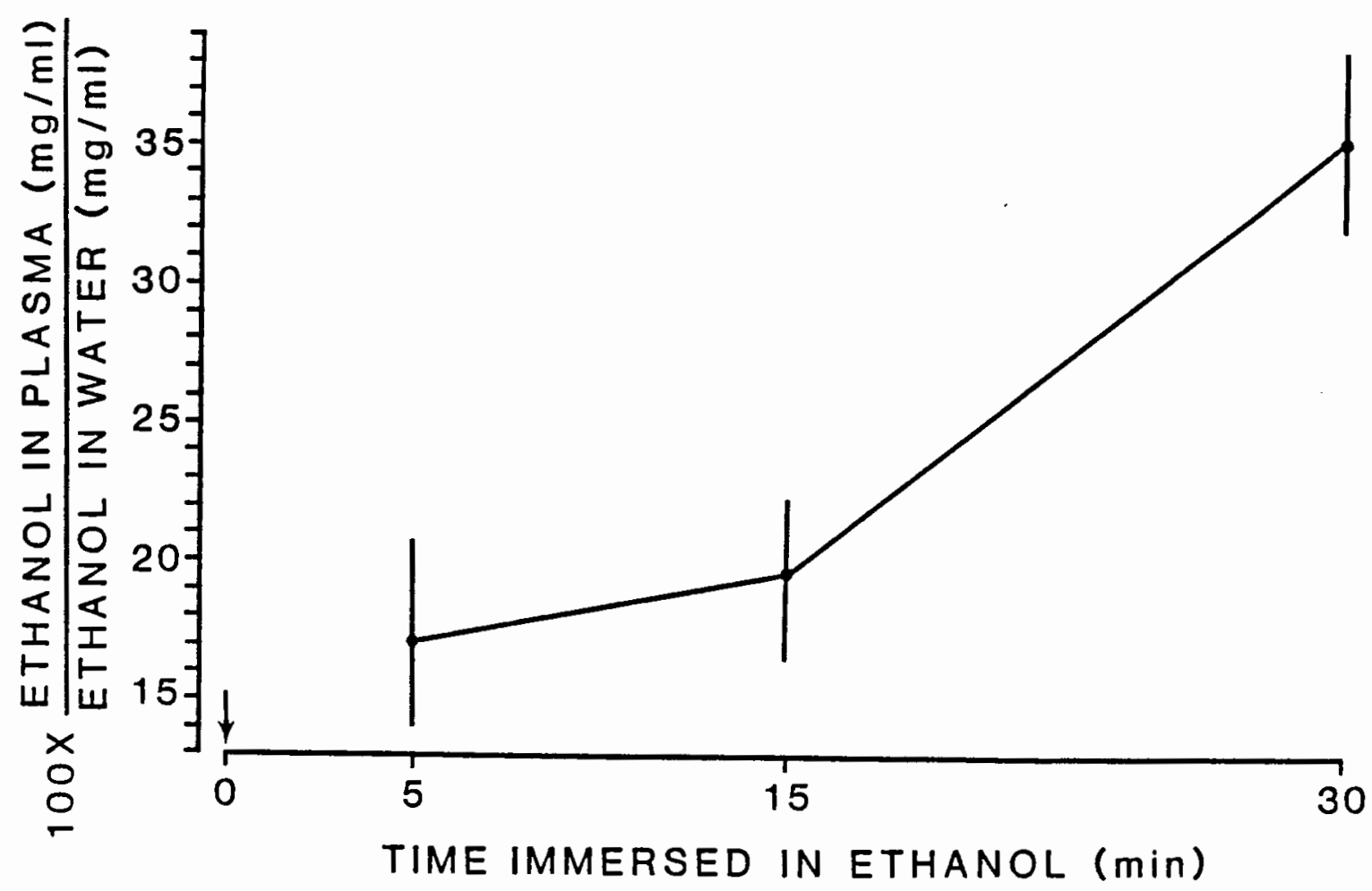

Figure 4. Change in ethanol concentration in fish plasma over time.

Fish were immersed in buckets containing room temperature water and $1.0 \%$ ethanol for five, fifteen, or thirty minutes. After the indicated time had elapsed, fish were removed from the water and blood samples obtained. Water samples were taken at the same time, to determine the exact ethanol concentration in the water at the time of sampling. Blood was obtained directly from the caudal artery of the dosed fish after a transverse cut was made completely through the tail just caudal to the anal fin. The blood samples were processed according to the following protocol (from the lab of John C. Crabbe). A $20 \mu \mathrm{l}$ glass pipette was filled with fish blood and immediately blown into a $1.5 \mathrm{ml}$ snap tube containing $50 \mu \mathrm{l}$ of $\mathrm{ZnSO}_{4}$ solution $\left(8.9 \mathrm{~g} \mathrm{ZnSO}_{4}\right.$ in $100 \mathrm{ml}$ distilled water). $50 \mu \mathrm{l}$ of saturated $\mathrm{BaSO}_{4}$ solution ( $4.73 \mathrm{~g}$ of $\mathrm{BaSO}_{4}$ in $100 \mathrm{ml}$ distilled water) and $300 \mu \mathrm{l}$ of distilled water were added to the tube, which was capped and then spun down for five minutes in a Beckman Microfuge B. The supernatant was 
decanted into a second snap tube and flash frozen, along with the snap tubes containing the water samples, in a solution of ethanol and dry ice. The frozen samples were transported to the Veteran's Administration Hospital for analysis of ethanol concentrations by gas chromatography.

The concentration of ethanol in the fish plasma is expressed as a percent of the concentration of ethanol in the water in which the fish were swimming. The fish were dropped into the buckets containing ethanol and water at time zero, indicated by an arrow on the graph. The points on the graph represent mean values $+/-1$ standard error (s.e.) for five fish at five minutes, four fish at fifteen minutes and five fish at thirty minutes. After five minutes the fish plasma contained about seventeen percent of the ethanol in the surrounding water. This concentration rose to about 19.5 percent after fifteen minutes and thirty five percent after thirty minutes. Ryback et al (1969) sampled blood ethanol levels of fish maintained in $0.4 \%$ and $0.65 \%$ ethanol for varying lengths of time up to five days. They found that the blood ethanol levels in their fish rose to a high of about $85 \%$ of the water ethanol concentration after three hours in either solution. Blood ethanol levels declined slightly to about $80 \%$ of the water ethanol level over the course of five days.

In the behavioral experiments data were typically collected for a half hour following a change in ethanol concentration. In that time, and over the course of a day, the ethanol concentration in the gradient falls slightly. But at the same time it is evident from Figure 4, and from Ryback et al's (1969) work, that the concentration of ethanol in the fish only slowly approaches the concentration of ethanol in the water. The concentration in the water represents a potential maximum concentration that fish approach, but evidently cannot reach even with extended periods of time in ethanol. Slow volatilization of ethanol from the gradient decreases the potential maximum ethanol concentration the blood of a fish could achieve. However, in practice the blood ethanol concentration is minimally affected, since during the course of these experiments the fish were not in ethanol for a long enough period of time to approach the maximum percent of ethanol in the water.

Two types of fish behavior were deemed unacceptable, and data gathered during episodes of such 
behavior was discarded. The first type occurred when a fish swam to very cold water and remained there, motionless. Some fish routinely responded this way to being caught. A fish that sat motionless at ten degrees was not exhibiting meaningful behavioral thermoregulation, and data collected during such episodes was not useful. In these studies the data for a fish was deleted for any treatment during which it remained in water fifteen degrees or colder for eight minutes or longer.

The second type of behavior that caused data to be discarded occurred when fish became too intoxicated to swim. A fish was considered too intoxicated to swim when it lost its ability to remain upright in the water. Intoxicated fish were removed between treatments. No fish was removed during a treatment, because fish in the other lanes became agitated when a person bent over the lanes.

Typically, fish were overcome by ethanol in one of the two ends of the gradient. Others have found that, in the absence of a water temperature gradient, a fish in a gradient apparatus will tend to spend much more of its time in the ends of the enclosure (Crawshaw and Hammel, 1973). Perhaps, as a fish became dysfunctional due to ethanol, the "end effect" attracted it despite the uncomfortably cold or lethally hot temperatures extant at those locations.

If a fish lost control of its swimming in the cold end of the gradient, it invariably revived successfully very soon after being placed in a bucket of room temperature water. The hottest chamber of each lane, however, was too hot for fish to tolerate for more than a few minutes. The temperature of about $36 \mathrm{C}$ at the hottest end of the gradient was at, or close to the upper lethal temperature for these fish that were housed at about $23 \mathrm{C}$ (Fry, 1964). Fish can lose their equilibrium from high temperature alone (Chavin, 1973), and from ethanol without high temperature (Greizerstein and Smith, 1973). Malcom and Alkana's (1983) work suggests that temperature influences the toxicity of ethanol; perhaps, at higher temperatures, increased membrane fluidity may enhance the ability of ethanol to reach sites of action in the cell membrane. Whether because of high temperature, ethanol, or the combination, a fish that swam into the hottest chamber of its lane was quickly incapacitated, then killed by the heat if it was not promptly removed. This situation accounted for the only accidental loss of animals that 
occurred during this series of experiments. 


\section{CHAPTER IV}

\section{RESULTS AND DISCUSSION}

The effect of ethanol on thermoregulation in the goldfish is illustrated in Figure 5, which shows temperatures selected by goldfish under the influence of increasing concentrations of ethanol. Vertical bars above and below each data point represent $+/-1$ s.e. Small numbers next to each point indicate the $\mathrm{n}$ for that point. Numbers of fish differ because data points represent a combination of more than one experiment, and because some fish were discarded according to the criteria set forth in the Materials and Methods section of this thesis.

Figure 5, Part A represents the lower part of the dose response curve. Data from two different experiments were combined to generate this curve. Fish were selected and introduced into the ethanolfree gradient, as described in Materials and Methods. Ethanol was added to the gradient beginning with the lowest dose $(0.1 \%$ ethanol). The concentration was increased by $0.1 \%$ increments until the same fish were exposed to the entire range of concentrations represented by this graph. Figure 5, Part B was generated in exactly the same way, except that more ethanol was added to begin with $(0.8 \%)$, and a higher final concentration was reached $(1.7 \%)$.

The result of increasing the concentration of ethanol is to lower the preferred temperature of goldfish. The portion of the dose response curve where the progression from no effect to maximal effect occurs is narrow. This progression probably begins around $0.5 \%$ ethanol, though at this concentration the difference between control and ethanol-dosed fish is not yet significant. A complete and statistically significant response is elicited by a concentration of $0.7 \%$ ethanol $(P=.05, t=2.69, \mathrm{df}=17)$. The effect does not become greater with concentrations of ethanol above $0.7 \%$. The dosed fish continue to select temperatures about two degrees below temperatures selected by control fish in water. 

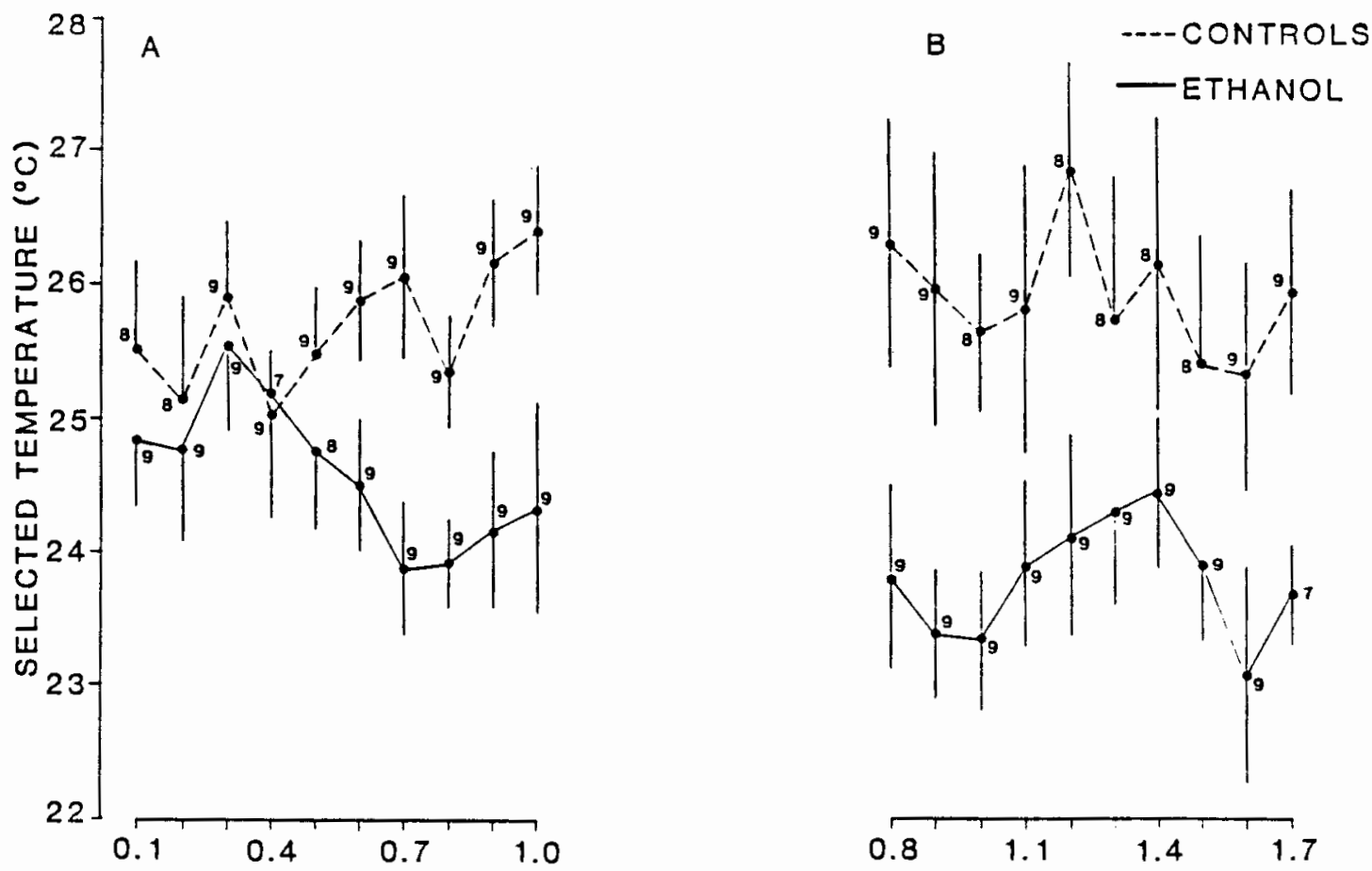

CONCENTRATION OF ETHANOL IN WATER OF GRADIENT (\%)

Figure 5. Effect of increasing concentration of ethanol on selected temperature of goldfish. (A) $0.1 \%$ to $1.0 \%$ ethanol. (B) $0.8 \%$ to $1.7 \%$ ethanol.

When fish are placed in a temperature gradient, they will gradually gravitate towards the point where acclimation temperature and preferred temperature are equal (Fry, 1964). In addition, goldfish exhibit daily cycles of preferred temperature (Hutchison and Maness, 1979). Because of these progressions and cycles, the preferred temperature of ethanol-dosed fish cannot be compared against some unchanging base line. The temperature selected by fish in ethanol can, however, be compared against the temperature selected by matching control fish which are presumably exhibiting the same cycles at the same time. To focus on the difference in preferred temperature of control and ethanol dosed fish, the data have been replotted in Figure 6. A Student's $t$-test showed that the values at ethanol concentrations of $0.8 \%, 0.9 \%$ and $1.0 \%$ that overlap in the two curves shown in Figure 5 were not different for the ethanol dosed fish, or for the matching control fish. Therefore the two curves were combined into one to produce Figure 6. 


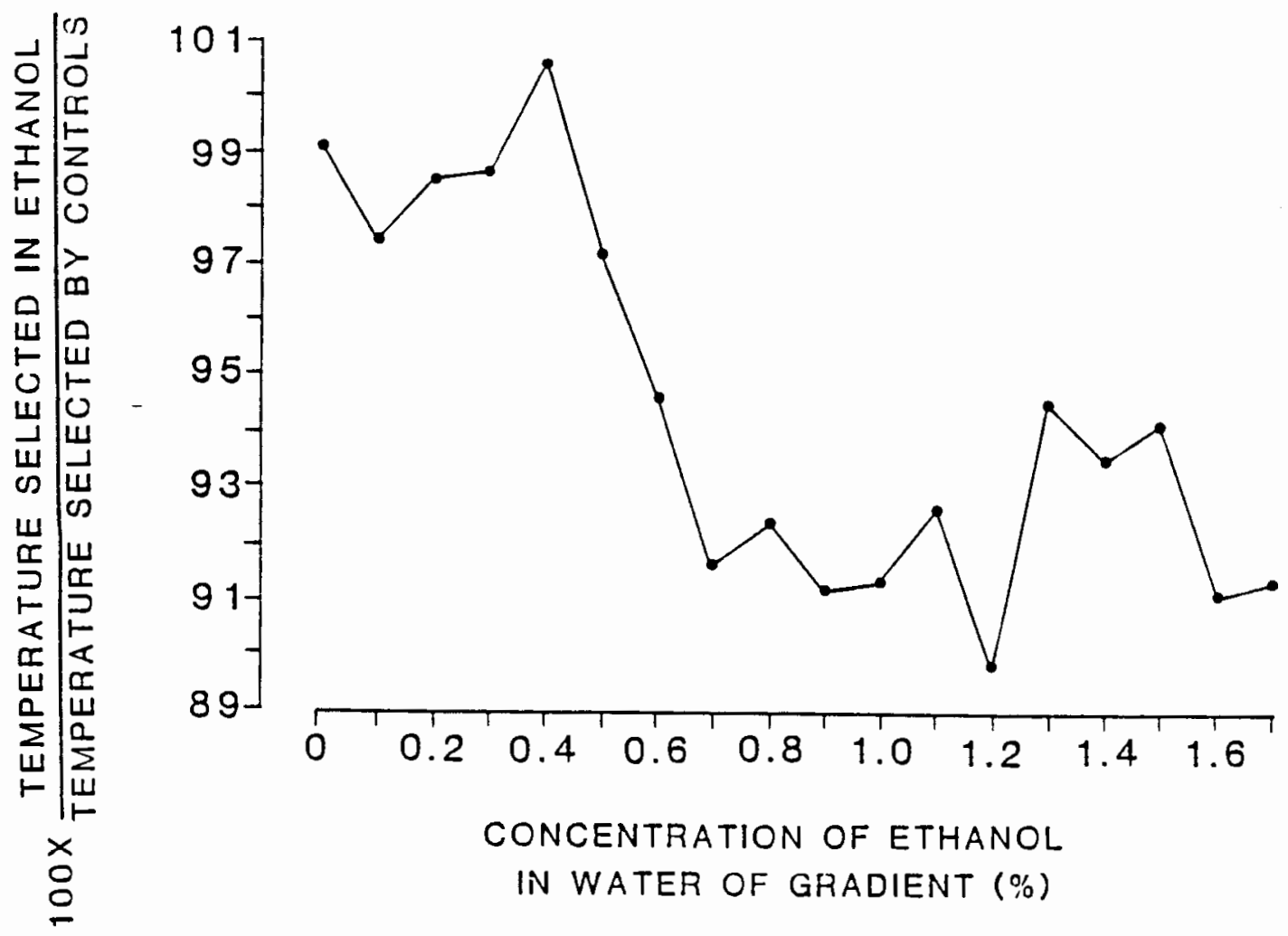

Figure 6. Temperature selected by goldfish in increasing concentrations of ethanol, expressed as a percent of temperature selected by matching control fish.

To obtain the data points in Figure 6, the mean selected temperature at each concentration of ethanol was divided by the mean temperature selected by matching control fish, and the result plotted as a percent. Figure 6 clearly shows that at the lowest concentrations of ethanol, the dosed fish selected about the same temperatures as did the matching controls. The decline in selected temperature that began at about $0.5 \%$ ethanol was precipitous; the mean selected temperature of the fish in ethanol decreased about $3 \%$ (nearly $0.5 \mathrm{C}$ ) for each $0.1 \%$ increase in ethanol concentration until a maximum effect of ethanol was achieved at a concentration of $0.7 \%$.

Many investigators have noted that the body temperature of ethanol-dosed endotherms will fall if the ambient temperature is below the thermoneutral zone; see for example Hirvonen and Huttunen (1977), Lomax et al (1981), Myers (1981), Walker et al (1982). However Haight and Keatinge (1973) 
found that ethanol resulted in increased heat loss only when accompanied by hypoglycemia. Myers (1981) found that at ambient temperatures above thermoneutrality, rats became hyperthermic; he termed ethanol a poikilothermic agent. James et al (1980) explored the possibility that ethanol might actually exert a thermogenic effect in hypothermic animals because of its high calorie content (such an effect could not be demonstrated). It seems that the question of exactly what effect ethanol exerts on endotherms has not yet been answered. Ethanol modifies such major thermoregulatory elements as nonshivering thermogenesis, shivering, respiratory depth and frequency, cutaneous blood flow, rate of sweat secretion, firing rates of neurons, and behavior (Kalant and Le, 1984). Effects on the central nervous system are not simply disentangled from effects on peripheral effector systems.

In the case of fish, the question of what the body temperature will do following a change in ambient temperature, with or without ethanol dosing, never arises. If the temperature of the water in which a fish is swimming changes, the temperature of the fish will change. Likewise, there is no question in fish of effector systems and set point at physiological conflict. Figures 5 and 6 illustrate clearly that, when dosed with an appropriate concentration of ethanol, fish will swim into cooler water than similar fish who have not been dosed with ethanol. Such behavior on the part of the dosed fish must be caused by ethanol; there is no other difference between control and experimental fish. The hypothalamic set point determines the preferred temperature of fish, and it seems likely that the effect of ethanol on the temperature regulation of fish is to lower the set point. Alternative explanations are, however, possible and ought to be considered.

As has been discussed (see the Literature Review section of this paper), ethanol might affect the temperature regulation of an organism in different ways. The set point might be abolished. A fish whose set point was abolished might avoid the hottest and coldest ends of its lane, because its pain receptors would function to warn it away from thermally inimical environments. Apart from avoiding extreme temperatures, one would expect such a fish to swim randomly back and forth through most of the temperature gradient. These fish did not swim randomly in ethanol. 
Ethanol might also act to broaden the set point, decreasing the precision of the thermoregulatory system and allowing larger oscillations in body temperature to occur. However, dosed fish seemed to thermoregulate more, not less precisely than controls; their activity levels seemed lower, and they spent less time "pacing" (swimming quickly from one end of the gradient to the other). The standard error of mean selected temperature was smaller for dosed fish at $0.7 \%$ to $1.7 \%$ ethanol, than for matching control fish for almost every pair of matching points. (The exceptions were slightly larger standard error for ethanol-dosed fish at $0.9 \%$ and $1.0 \%$ in Figure $5 \mathrm{~A}$, and $1.1 \%$ in Figure $5 \mathrm{~B}$.) The size of the standard error might increase with smaller sample size as well as with decreased thermoregulatory precision. But the numbers of individuals in dosed and control groups are similar or the same for each set of points; therefore, the consistently smaller standard error for dosed fish probably indicates increased thermoregulatory precision. Ethanol did not appear to abolish or broaden the set point in these fish.

Ethanol might exert an effect through systems other than the central controllers of temperature regulation. As has been discussed, a major advantage of the use of fish in this type of study is that effects on effectors will not alter the temperature selection of the animal. But if, for example, ethanol were affecting thermodetectors in a uniform way, input to the central controller might be skewed in one direction resulting in faise temperature readings and altered temperature selection. Ethanol's effects on membranes might result in a change in neurotransmitter release, or uptake, or both, at the neuronal synapse. Membrane effects might alter the ability of a cell to take up some hormone or hormones that normally play a role in the organism's response to heat or cold.

Alternative explanations for the effect of ethanol on temperature selection of goldfish are possible. However, these experiments were able to measure behavior only. The conclusion that the set point of these fish was altered seems plausible and reasonable based on the behavior observed. Temperature selection was the only variable scrutinized during these experiments. It is not known whether alcohol exposure affected vasoconstriction, metabolic rate, respiration rate or any physiological parameter other than temperature selection. 
Figure 7 illustrates the effect of $1.0 \%$ ethanol over a longer span of time. The intent of this inquiry was to determine whether short-term tolerance to ethanol could develop over the span of time typically covered by an experiment. Presumably, any tolerance that developed would have been evidenced by a rise in the temperature of ethanol-treated fish, after some period of time spent at a lowered temperature. This was not observed.

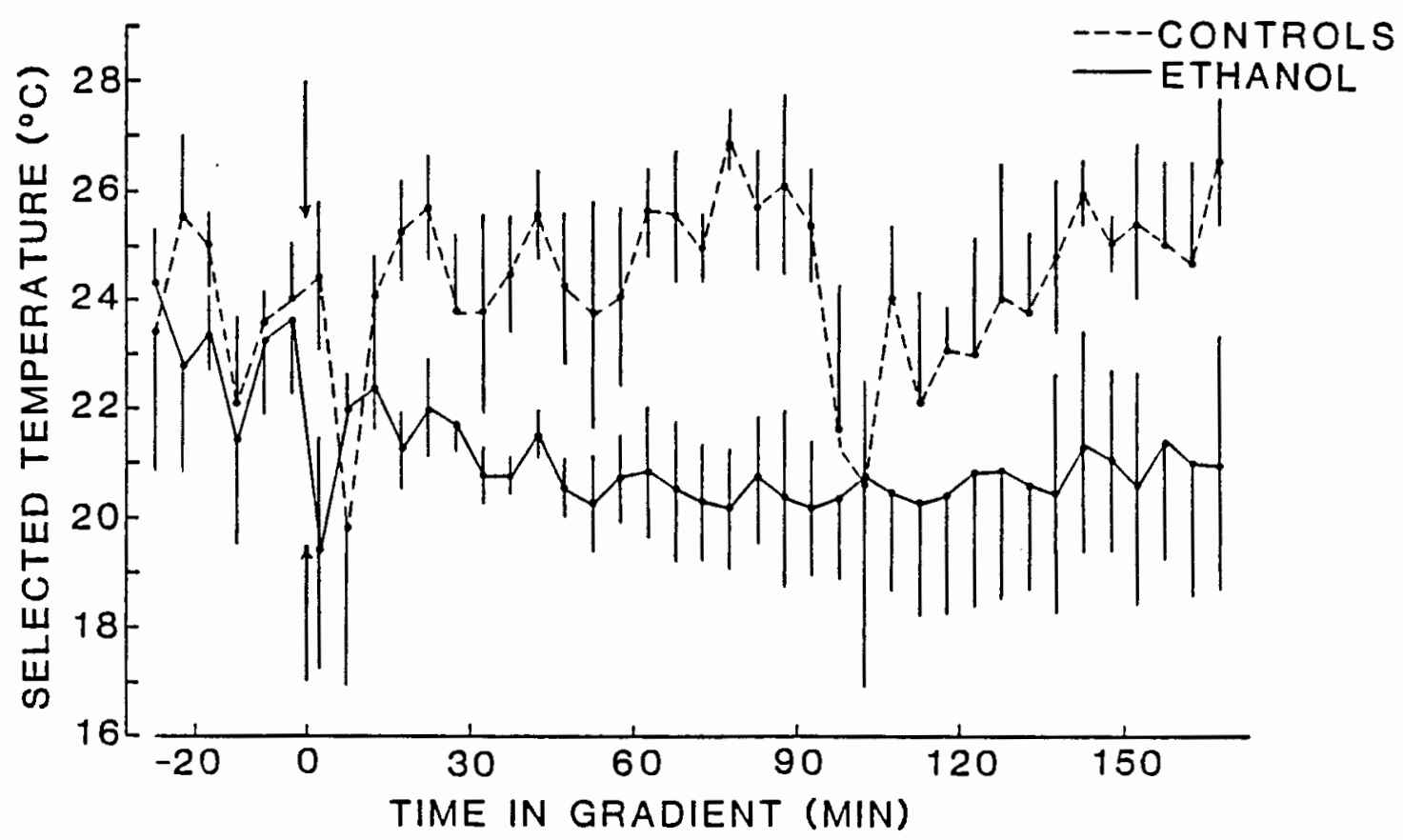

Figure 7. Effect of exposure to $1.0 \%$ ethanol for $3 \mathrm{hr}$ on selected temperature of goldfish.

Average selected temperature for consecutive five minute periods is shown for four control fish (the dashed line) and five fish exposed to $1.0 \%$ ethanol (the solid line). Again, vertical bars represent +/- 1 s.e. The first six points (to the left of the arrows) represent temperatures selected before ethanol was added to the lanes containing the experimental fish. Less than fifteen minutes after ethanol was added the treated fish began to select colder temperatures than the controls, and remained in colder water until the end of the experiment. Both control and treated fish showed a transient period of very 
low temperature selection after ethanol was added. A brief sojourn by the fish into cold water after being released from the mesh corrals was a fairly common phenomenon. The pronounced dip in selected temperature of the control fish that is indicated about $1 \mathrm{hr} 45 \mathrm{~min}$ after addition of ethanol to the gradient, is due to two control fish choosing atypically low temperatures for a while.

Acute tolerance is a term used to designate tolerance occurring during the course of a single exposure to a drug (Kalant and Le, 1984). This type of tolerance to the effects of ethanol, including the hypothermic effect, has been observed in the rat 30 to $60 \mathrm{~min}$ after intraperitoneal injection of ethanol (LeBlanc et al, 1975), and in the mouse during a six hour exposure to ethanol vapor (Grieve and Littleton, 1979). Greizerstein and Smith (1973) examined brain ethanol levels in fish at overturn (the point at which the fish lost its equilibrium). They found that tolerance, measured by increased brain ethanol content at overturn, developed in goldfish after as little as $3 \mathrm{hr}$ exposure to $0.8 \%$ ethanol. Their work supports the conclusion that can be drawn from the data represented in Figure 7; for exposure to ethanol under $3 \mathrm{hr}$ in duration, development of acute tolerance with accompanying mitigation of the effect of ethanol on temperature selection is not observed in the goldfish.

Figure 8 illustrates the time course of the onset and disappearance of the effect of ethanol on temperature selection. The first point on the curve represents a $30 \mathrm{~min}$ average of selected temperature for all six fish in this experiment. Each subsequent point represents mean selected temperature for all six fish for one minute. The data points located over the black bars were collected while the fish were immersed in $1.0 \%$ ethanol. The middle data points located over the clear bar represent temperature selection in water. After the $30 \mathrm{~min}$ average baseline selected temperature was recorded, the fish were placed in $1.0 \%$ ethanol for approximately $30 \mathrm{~min}$, removed to water for $30 \mathrm{~min}$, then returned to the ethanol-dosed water. Standard error bars were omitted for clarity. The range of one standard error was 0.4 to $2.32 \mathrm{C}$, with an average standard error of $1.16 \mathrm{C}$.

Figure 8 clearly shows a prompt decrease in the temperature selected by goldfish when they are placed in water containing ethanol, and a return to higher selected temperature when fish are returned to 


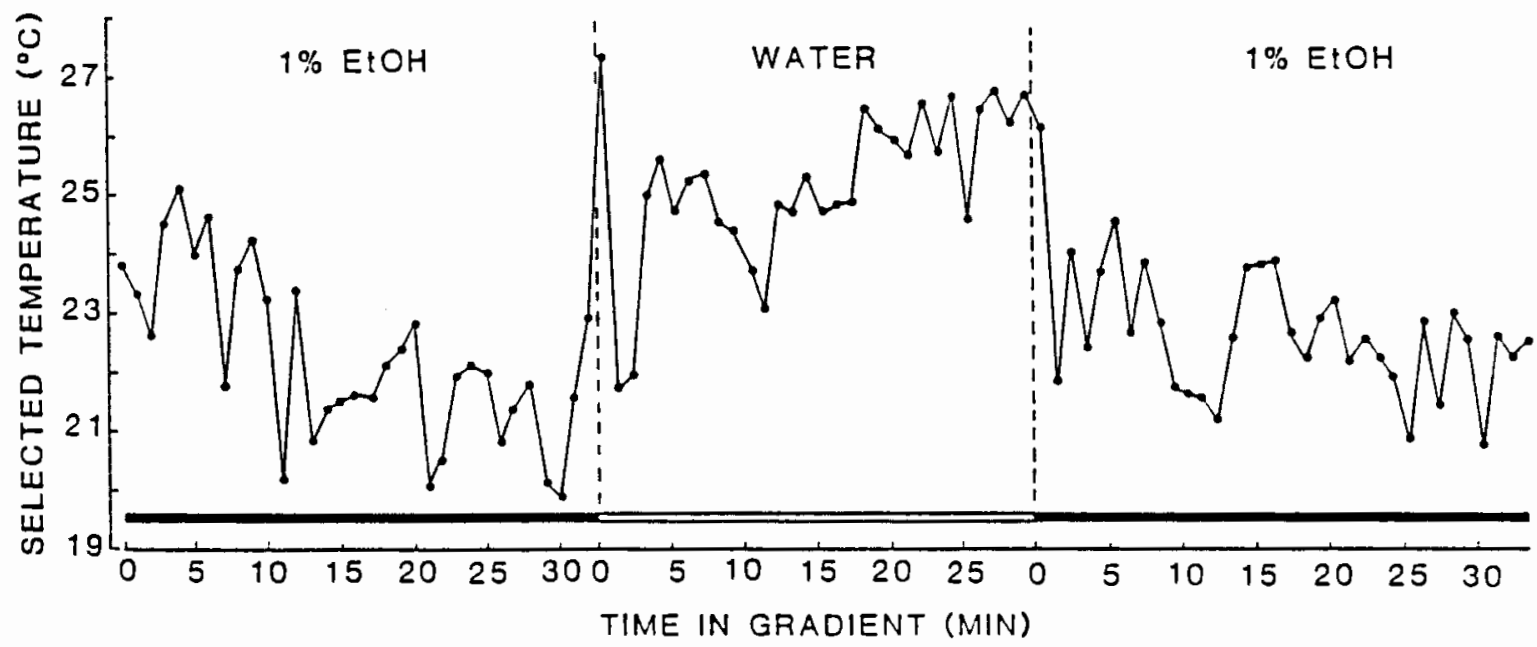

Figure 8. Effect of alternating exposure to $1.0 \%$ ethanol and water on the temperature selection of goldfish.

water without ethanol. The effect of ethanol, though rapid, is not instantaneous. To allow the effect to reach full expression (or to disappear fully) the first $15 \mathrm{~min}$ in ethanol or in water was discarded and ANOVA was used to compare the temperatures selected by these fish for the second half of each bout in ethanol with temperatures selected for the same time period in water. ANOVA showed that there was no difference in temperatures selected during either bout in ethanol, but that temperature selection in water was different from temperature selection during either ethanol exposure.

When placed in water, the preferred temperature of these fish rose over the course of $30 \mathrm{~min}$. Preferred temperature probably rose in water for two reasons. The ethanol caused the fish to select cooler temperatures. After they were moved to water, as the ethanol was flushed out of their systems, the effect diminished and disappeared. In addition, the preferred temperature of these fish, in the absence of ethanol, would have been rising since their introduction into the gradient. Note the comparatively low initial preferred temperature (the first point on the curve, representing a 30 min pre-treatment average selected temperature). The depressing effect of ethanol masks the gradual rise of preferred tempera- 
ture that these goldfish typically exhibit when placed in the temperature gradient.

The next section of this discussion will examine technical and statistical problems encountered in collecting and analyzing this data.

When fish are placed in a temperature gradient, they will gradually gravitate towards the point where acclimation temperature and preferred temperature are equal (Fry, 1964). The final thermal preferendum of goldfish is about $28 \mathrm{C}$. It is known that goldfish exhibit daily cycles of preferred temperature, which may be influenced by a combination of acclimation temperature and photoperiod (Hutchison and Maness, 1979).

Fish were often left in the gradient for several hours at a time in the course of these experiments. Because they were housed at about $23 \mathrm{C}$, a temperature lower than their final thermal preferendum, it would be expected that their preferred temperature would show a gradual rise throughout the day. Reynolds and Casterlin (1979) suggest that the "optimal period for testing acute preferenda occurs within 2 hrs or less after placement in the gradient, in order to minimize the effect of gravitational reacclimation toward the final preferendum." When fish were first placed in the gradient for any of these experiments, they spent most of their time at a lower temperature than they chose at the end of the day, as expected. When first placed in the gradient most fish also showed very high activity, which is easy to understand; they had just been netted out of their familiar home tank with dark walls, hiding places and companions, and dropped into the white-walled, sterile solitude of a lane of the gradient. No matter how many hours of training fish had previously experienced, they were restless (some more than others) when first introduced into the gradient. Therefore they were allowed to acclimate for $30 \mathrm{~min}$ to an hour (or more) before the recording of baseline data (pre-ethanol data) was begun. By the time ethanol was added, the fish were nearly or completely past Reynolds and Casterlin's 2 hr "optimal period for testing acute thermal preferenda". But it seems that little was lost, because these fish seemed never to exhibit such an "optimal period" of presumably stable initial temperature preference. The preferred temperature of these fish, in the absence of ethanol, showed a slow but steady rise beginning very soon after their 
introduction into the gradient. This should be kept in mind when considering the data.

Standard errors were large for many of these treatments. This is due in some cases to a small number of fish, and in others to the variability of individual fish. Various nonthermal factors can affect the acclimatization state of an animal (from Reynolds and Casterlin, 1979) including photoperiod or other seasonal influences, salinity, time of day, light, age, chemicals, biotic interactions, bacterial pyrogens, nutritional state and other factors. Most of these factors were probably similar for all fish. Environmental factors such as light, chemicals and salinity were certainly the same. These fish were purchased from a fish farm, where they were housed in big pools of same-age groups; although they vary in size, they probably are of a similar age. All fish were fed together. It is possible that more aggressive individuals ate more, but the fish were fed generously, and it is more likely that every fish had a chance to eat its fill.

These fish never had problems with sickness or parasites. Not one of the group was lost to disease, and months after the last of these experiments the fish remain robust and healthy. In any case, pyrogens cause fish to select warmer water, and sick fish are known (Crawshaw, 1980; Kluger, 1979) to choose warmer-than-usual water. Most of our anomalous fishes go into cold water and become inactive. This is not the sort of behavior one would expect from sick fish. This type of behavior has been observed (though not explained) in Channel catfish also (author, personal observation). Unfortunately, it is impossible to logically separate cold inactivated fish from fish whose set point has been changed, since behavior is all these experiments monitor.

The response of swimming into very cold water may provide an example of what Neill (1979) has termed "predictive thermoregulation". Neill postulates that, if a fish lives in an environment characterized by a temporally and spatially predictable thermal structure, it evolves or learns information about that thermal structure that enables it to make rapid behavioral thermoregulatory adjustments (predictive thermoregulatory responses) to solve a problem, such as attack by a predator, or to gain something, such as food. Perhaps goldfish have evolved (or individually learn) a cold-seeking behavior 
to deal with certain threats in their natural world. An attack by a bird, for example, might be thwarted by a fish that rapidly swam to deeper, colder water. However, as Neill also observes, "An obvious shortcoming of predictive thermoregulation is that it may become suddenly and drastically maladaptive when the environmental system changes." Being dropped into an artificial temperature gradient, for a pond-reared goldfish, certainly constitutes an environmental system change. Perhaps the defensive behavior of swimming into cold water is evoked, in some fish, by the gradient surround itself, or by the trauma of being netted or caged. This could be an individually learned response in goldfish, depending upon whether an individual fish had successfully escaped a predator in the past by utilizing the response. Equally possible is that it is an innate, evolved response. The non-homogeneous genetic background of these fish that can be inferred from phenotypic and behavioral variations among them might explain why some goldfish, but not others, exhibit this behavior.

A few control fish habitually responded to being caught and released by swimming to the coldest end of the gradient and becoming inactive there. This was a persistent problem. Ethanol-treated fish were not observed to behave this way. Data collected from the inactive fish could be discarded, according to criteria explained in the Materials and Methods section. A similar problem, but one more difficult to deal with, was posed by control fish that chose to remain at obviously colder-than-normal water, $16 \mathrm{C}$ to $21 \mathrm{C}$, but did not meet the criteria established for cold-inactive fish. This happened with fair frequency, and is difficult to explain. Ethanol leakage into control lanes of the gradient is not a possible explanation. The lanes were isolated from one another with shut-off valves, and gas chromatographic analysis of the water from control lanes showed no ethanol content. Perhaps these fish were cold-inactive also, but at a less extreme temperature. No guidelines were developed that would allow data from these suspicious fish to be discarded. If one control fish chooses $20 \mathrm{C}$ while three or four other controls choose $26 \mathrm{C}$ to $28 \mathrm{C}$, not only will the average selected temperature be decreased, but also the size of the standard error will increase. It is a measure of the robustness of the effect that despite this problem (which was very frequent) statistically significant differences between the temperatures selected by control and ethanol-treated fish remain. 
These fish are individuals. They have not been bred to be genetically identical. The size, shape and color differences between them are only the first indication of how different each fish is from its fellows. There are very obvious differences in the behavior of individuals in the gradient. Some fish seem to realize quickly that there is no food, companion or hiding place available in the gradient, and that the only comfort factor in their environment they can affect, is the ambient temperature. These fish quickly settle down in the region of the gradient that is comfortable for them. They do little exploratory swimming, and the swimming they do does not take them far from their preferred region. Other fish never seem to calm down in the gradient. They swim from one end of the gradient to the other and back again, ceaselessly. These pacing fish introduce a large standard error also. While the average temperature they select may be similar to the average temperature selected by calmer fish in neighboring lanes, their very high level of activity introduces a lot of noise into the data.

Where standard errors of selected temperature are shown (Figures 5 and 7) they are drawn above and below each point. Thus they imply an equal probability that a fish will be found one standard error above or below the mean. The temperature distributions of ectotherms that are free to select any of a wide range of temperatures are usually negatively skewed (DeWitt and Friedman, 1979). In terms of the standard error, this implies that the animal is not equally likely to be found at a given distance above or below the mean selected temperature. Reynolds and Casterlin (1979) suggest that distributions of preferred temperature may be skewed for reasons intrinsic to the biology of an organism. The final thermal preferenda of many ectotherms, including warmwater fishes, are often within a few degrees Centigrade of the upper lethal temperature (Reynolds and Casterlin, 1979), so the upper limit tends to be regulated more precisely than the lower limit. However, frequency histograms constructed from some of the data discussed in this thesis (histograms not shown) did not show evidence of negative skewness. Rather, they showed fish positions tending towards a symmetrical distribution about the mean, as implied by the standard error bars.

Why would these goldfish be distributed evenly on either side of their mean selected temperature? The probable explanation is that they were never in the gradient long enough to reach their final 
thermal preferendum, which Fry (1964) defined as the point to which fish would gravitate, if left infinitely long in a temperature gradient, where acclimation temperature and preferred temperature are equal. If mean selected temperature was still edging upward toward the final thermal preferendum, the fish would be expected to continually make forays into warmer water as they sought and gradually adjusted to ever increasing ambient temperature. 


\section{CHAPTER V}

\section{CONCLUDING STATEMENT}

Ethanol produces a change in the thermoregulatory behavior of goldfish. This change is initiated within a narrow range of ethanol concentrations, between about $0.5 \%$ and $0.7 \%$ ethanol. Ethanol at these and higher concentrations causes goldfish, as long as they can still swim successfully, to choose temperatures about $2 \mathrm{C}$ colder than temperatures chosen by matching control fish in water. Goldfish do not seem to develop rapid tolerance to the effect of ethanol on the thermoregulatory system.

According to Euler (1961), drug-induced actions on central thermoregulatory mechanisms may be due to effects on three different mechanisms:

1. hypothalamic thermodetectors.

2. referencing and setting mechanisms for the body thermostat.

3. hypothalamic relays for coordination of the regulation.

Effects on thermodetectors might lessen their accuracy and efficiency, rendering an animal in whom these effects occurred less able to correctly perceive the temperature of its environment. One would expect such an animal to exhibit randomized temperature selection. Random temperature selection by fish as a result of ethanol administration was not observed in this series of experiments. If anything, dosed fish regulated their temperature more precisely than did control fish in water.

Membrane effects of ethanol might alter neuronal firing rates, changing the thermodetector signal to the hypothalamic relays uniformly in one direction and resulting in precise thermoregulation around a new temperature. Since these experiments measured only behavior, it is not possible to assess the likelihood of this alternative explanation based on the data presented here. 
If the coordination of the temperature regulation system were destroyed, control of effector systems by the central thermoregulatory elements would be lost. Feedback to the central elements might cease. An animal would not be able to successfully thermoregulate, and again a randomized swimming pattern in the temperature gradient would be perceived.

If the setting mechanism alone were altered, an animal's ability to thermoregulate would not be impaired. Accurate information from thermodetectors would still be received and interpreted properly, and regulation would proceed successfully and precisely, focused around a new temperature. For a fish, such a change in set point would be evidenced by a change in the temperature of the water in which the fish chose to spend most of its time, in the absence of other motivating factors such as fright or hunger. An ethanol-induced change in the set point of fish is a plausible explanation for the precise thermoregulation around an altered temperature shown by the ethanol treated fish in this series of experiments. 


\section{BIBLIOGRAPHY}

Bardach, J.E. and R.G. Bjorklung. The temperature sensitivity of some American freshwater fishes. Amer. Nat. 91: 233-251, 1957.

Baum, R. and F.L. Iber. Alcohol, the pancreas, pancreatic inflammation, and pancreatic insufficiency. Am. J. Clin. Nutrition 26: 347-351, 1973.

Beevers, D.G. Alcohol and hypertension. Lancet 2(8029): 114-115, 1977.

Beitinger, T.L. and L.C. Fitzpatrick. Physiological and ecological correlates of preferred temperature in fish. Am. Zool. 19: 319-329, 1979.

Blackwelder, W.C., K. Yano, G.G. Rhoads, A. Kagan, T. Gordon and Y. Palesch. Alcohol and mortality: The Honolulu heart study. Am. J. Med. 68: 164-168, 1980.

Bligh, J. The thermosensitivity of the hypothalamus and thermoregulation in mammals. Biol. Rev. 41: $317-367,1966$.

Brunt, P.W., M.C. Kew, P.J. Scheuer and S. Sherlock. Studies in alcoholic liver disease in Britain. Gut 15: 52-88, 1974.

Clark, P. and L. Kricka. Medical Consequences of Alcoholism. New York: John Wiley and Sons, 1980.

Cobo, E. and C.A. Quintero. Milk-ejecting and antidiuretic activities under neurohypophyseal inhibition with alcohol and water overload. Am. J. Obs. Gyn. 105: 877-887, 1969.

Crabbe, J.C., J. Janowski, E. Young, A. Kosobud, J. Stack and H. Rigter. Tolerance to ethanol hypothermia in inbred mice: Genotypic correlation with behavioral response. Alcoholism: Clin. Exper. Res. 6: 446-458, 1982.

Crawshaw, L.I. Responses to rapid temperature change in vertebrate ectotherms. Am. Zool. 19: 225 - 
$237,1979$.

Crawshaw, L.I. Temperature regulation in vertebrates. Ann. Rev. Physiol. 42: 473-491, 1980.

Crawshaw, L.I. and H.T. Hammel. The regulation of internal body temperature in the brown bullhead, Ameiurus nebulosus. The Pharmacology of Thermoregulation. Symposium, San Francisco 1972, pp. 142-145 (Karger, Basel 1973).

Crawshaw, L.I., B.P. Moffitt, D.E. Lemons and J.A. Downey. The evolutionary development of vertebrate thermoregulation. Amer. Scientist 69: 543-550, 1981.

Daves, L., J. Miller, C. Lemmi and J. Thompson. Mechanism and inhibition of alcohol-stimulated gastric secretion. Surgical Forum 16: 305-307, 1965.

DeWitt, C.B. and R.M. Friedman. Significance of skewness in ectotherm thermoregulation. Am. Zool. 19: 195-209, 1979.

Dizon, A.E. and R.W. Brill. Thermoregulation in tunas. Am. Zool. 19: 249-265, 1979.

Eckhardt, M., T. Harford, C. Kaelber, E. Parker, L. Rosenthal, R. Ryback, G. Salmoiraghi, E. Vanderveen and K. Warren. Health hazards associated with alcohol consumption. J. Am. Med. Assoc. 246(6): 648-666, 1981.

Edmondson, H.A. Pathology of Alcoholism. Am. J. Clin. Path. 74: 725-742, 1980.

Elwin, C. Stimulation of gastric acid secretion by irrigation of the antrum with some aliphatic alcohols. Acta Physiol. Scand. 75: 1-11, 1969.

Ettinger, P., C. Wu, C. De La Cruz, A. Weisse, S. Ahmed and T. Regan. Arrhythmias and the "Holiday Heart": Alcohol-associaled cardiac rhythm disorders. Am. Heart J. Med. 95: 555-562, 1978.

Euler, C. von. Physiology and pharmacology of temperature regulation. Pharmacol. Rev. 13: 361-398, 1961.

Freund, G. Ethanol-induced changes in body temperature and their consequences. In: Majchrowicz, E. and E.P. Noble, eds. Biochemistry and Pharmacology of Ethanol, Volume 2. New York: Plenum 
Press, 1979, pp. 439-452.

Fry, F.E.J. Animals in aquatic environments: Fishes. In: Dill, A. and P. Wilber. Handbook of Physiology, Volume 4. Adaptation to the Environment. Washington: American Physiological Society, 1964, pp. 715-718.

Funk \& Wagnalls Standard College Dictionary. New York: Funk \& Wagnalls Publishing Co., 1973.

Goodwin, D.W., C.P. Dowd and S.B. Guze. Biphasic and reversible adaptation of goldfish to alcohol. Nature 232: 654-655, 1971.

Gordon, G.G. and A.L. Southren. Metabolic effects of alcohol on the endocrine system. In: Lieber, C.S., ed. Metabolic Aspects of Alcoholism. Baltimore: University Park Press, 1977, pp. 249-302.

Greizerstein, H.B. and C.M. Smith. Development and loss of tolerance to ethanol in goldfish. J. Pharm. and Exper. Ther. 187: 391-399, 1973.

Greizerstein, H.B. and C.M. Smith. Ethanol in goldfish: effect of prior exposure in a test procedure. Psychopharm. 38: 345-349, 1974.

Grieve, S.J. and J.M. Littleton. Age and strain differences in the rate of development of functional tolerance to ethanol by mice. J. Pharm. Pharmac. 31: 696-700, 1979.

Guernsey, D.L. and E.D. Stevens. The cell-membrane sodium pump as a mechanism for increasing thermogenesis during cold acclimation in rats. Science 196: 908-910, 1977.

Haight, J.S.J. and W.R. Keatinge. Failure of thermoregulation in the cold during hypoglycaemia induced by exercise and ethanol. J. Physiol. 229: 87-97, 1973.

Hainsworth, F.R. Saliva spreading, activity, and body temperature regulation in the rat. Am. J. Physiol. 212: $1288-1292,1967$.

Hammel, H.T. Regulation of internal body temperature. Ann. Rev. Physiol. 30: 641-710, 1968.

Hardy, J.D. Physiology of temperature regulation. Physiol. Rev. 41: 521-606, 1961. 
Hensel, H. Neural processes in thermoregulation. Physiol. Rev. 53: 948-1017, 1973.

Hirvonen, J. and P. Huttunen. The effect of ethanol on the ability of guinea pigs to withstand severe cold exposure. Drugs, Biogenic Amines and Body Temperature. 3rd Symp. on the Pharmacology of Thermoregulation, Banff, Alta. 1976, pp. 230-232 (Karger, Basel 1977).

Hutchison, V. and J.D. Maness. The role of behavior in temperature acclimation and tolerance in ectotherms. Am. Zool. 19: 367-384, 1979.

James, M.F.M., A. van den Berg, N.A. French and J.F. White. A study of the thermogenic effect of ethanol in the hypothermic rat. Clin. Exper. Pharmac. Physiol. 8: 118-123, 1981.

Jones, K.L. and D.W. Smith. Recognition of the fetal alcohol syndrome in early infancy. Lancet 2: 999-1001, 1973.

Kalant, H. and A.D. Le. Effects of ethanol on thermoregulation. Pharmac. Ther. 23: 313-364, 1984.

Kluger, M.J. Fever in ectotherms: Evolutionary implications. Am. Zool. 19: 295-304, 1979.

LeBlanc, A.E., H. Kalant and R.J. Gibbins. Acute tolerance to ethanol in the rat. Psychopharmacologia (Berlin) 41: 43-46, 1975.

Leevy, C.M. Fatty liver: A study of 270 patients with biopsy-proven fatty liver and a review of the literature. Medicine 41: 249-276, 1962.

Levy, Sheldon G. Inferential Statistics in the Behavioral Sciences. New York: Holt, Rinehart and Winston Inc., 1968.

Lieber, C.S. Hepatic and intestinal injury after chronic ethanol consumption. In: Chafetz, M.E., ed. $\underline{\text { Proceedings of the Fourth Annual Alcoholism Conference of the National Institute on Alcohol }}$ Abuse and Alcoholism. Rockville, Md: NIAAA, 1975, pp. 171-182.

Lomax, P., J.G. Bajorek, T-A. Bajorek and R.R.J. Chaffee. Cold acclimation and the hypothermic effect of ethanol in the rat. Proc. West. Pharmacol. Soc. 24: 33-36, 1981.

Magnuson, J.J., L.B. Crowder and P.A. Medvick. Temperature as an ecological resource. Am. Zool. 
19: 331-343, 1979. Malcom, R.D. and R.L. Alkana. Temperature dependence of ethanol lethality in mice. J. Pharm. Pharmacol. 35: 306-311, 1983.

Mancillas, J.R., G.R. Siggins and F.E. Bloom. Systemic ethanol: Selective enhancement of responses to acetylcholine and somatostatin in hippocampus. Science 231: 161-163, 1986.

Martin, D.C., J.C. Martin and A.P. Streissguth. Sucking frequency and amplitude in newborns as a function of maternal drinking and smoking. In: Galanter, M., ed. Currents in Alcoholism, Volume $\underline{5}$. New York: Grune \& Stratton, Inc., 1979, pp. 359-366.

McCauley, R.W. and N.W. Huggins. Ontogenetic and non-thermal seasonal effects on thermal preferenda of fish. Am. Zool. 19: 267-271, 1979.

Myers, R.D. Alcohol's effect on body temperature: hypothermia, hyperthermia or poikilothermia? Brain Res. Bull. 7: 209-220, 1981.

National Institute on Alcohol Abuse and Alcoholism. Second Special Report to the United States Congress on Alcohol and Health from the Secretary of Health, Education, and Welfare, December, 1971. DHEW Pub. No. (ADM)7.6-359. Washington, D.C.: Supt. of Docs., U.S. Govt Printing Off., reprinted 1976.

National Institute on Alcohol Abuse and Alcoholism. Third Special Report to the United States Congress on Alcohol and Health from the Secretary of Health, Education and Welfare. June 1978. Technical Support Document. DHEW Pub. No. (ADM)79-832. Washington, D.C.: Supt. of Docs., U.S. Govt. Print. Off., 1979.

National Institute on Alcohol Abuse and Alcoholism. Fourth Special Report to the United States Congress on Alcohol and Health from the Secretary of Health and Human Services. January, 1981. DHHS Pub. No. (ADM)81-1080. Washington, D.C.: Supt. of Docs., U.S.Govt. Print. Off., 1981.

Neill, W.H. Mechanisms of fish distribution in heterothermal environments. Am. Zool. 19: 305-317, 1979. 
Reynolds, W.W. and M.E. Casterlin. Behavioral thermoregulation and the "final preferendum" paradigm. Am. Zool. 19: 211-224, 1979.

Rottenberg, H., A. Waring and E. Rubin. Tolerance and cross-tolerance in chronic alcoholics: reduced membrane binding of ethanol and other drugs. Science 213: 583-585, 1981.

Ryback, R. The use of fish, especially goldfish, in alcohol research. Quart. J. Stud. Alc. 31: 162-166, 1970.

Ryback, R., B. Percarpio and J. Vitale. Equilibration and metabolism of ethanol in the goldfish. Nature 222: 1068-1070, 1969.

Schmidt-Nielsen, K. Animal Physiology: Adaptation and Environment. Cambridge: Cambridge University Press, 1983.

Simon, E. Temperature regulation: The spinal cord as a site of extrahypothalamic thermoregulatory functions. Rev. Physiol. Biochem. Pharmacol. 71: 1-76, 1974.

Smith, E.N. Behavioral and physiological thermoregulation in crocodilians. Am. Zool. 19: 239-247, 1979.

Snedecor, G.W. and W.G. Cochran. Statistical Methods. Ames: Iowa State University Press, 1982.

Song, S.K. and E. Rubin. Ethanol produces muscle damage in human volunteers. Science 175: $327-$ 328, 1972.

Stein, S., C. Lieber, C. Leevy, G. Cherrick and W. Abelmann. The effect of ethanol upon systemic and hepatic blood flow in man. Am. J. Clin. Nut. 13: 68-74, 1963.

Walker, P.Y., K.F.A. Soliman and C.A. Walker. Diurnal rhythm of ethanol hypothermic action in mice. Res. Commun. in Subst. Abuse 3(4): 503-506, 1982.

Wallgren, H. and H. Barry III. Actions of Alcohol, Volume 1. New York: Elsevier, 1970.

Zar, J.H. Biostatistical Analysis, 2nd Edition. Englewood Cliffs, N.J.: Prentice-Hall Inc., 1974. 